\title{
Inhibition of cell migration by focal adhesion kinase: Time-dependent difference in integrin-induced signaling between endothelial and hepatoblastoma cells
}

\author{
HONGCHI YU, MIN GAO, YUNLONG MA, LIJUAN WANG, YANG SHEN and XIAOHENG LIU \\ Institute of Biomedical Engineering, West China School of Basic Medical Sciences and Forensic Medicine, \\ Sichuan University, Chengdu, Sichuan 610041, P.R. China
}

Received June 6, 2016; Accepted January 31, 2018

DOI: $10.3892 /$ ijmm.2018.3512

\begin{abstract}
Angiogenesis plays an important role in the development and progression of tumors, and it involves a series of signaling pathways contributing to the migration of endothelial cells for vascularization and to the invasion of cancer cells for secondary tumor formation. Among these pathways, the focal adhesion kinase (FAK) signaling cascade has been implicated in a variety of human cancers in connection with cell adhesion and migration events leading to tumor angiogenesis, metastasis and invasion. Therefore, the inhibition of FAK in endothelial and/or cancer cells is a potential target for anti-angiogenic therapy. In the present study, a small-molecule FAK inhibitor, 1,2,4,5-benzenetetramine tetrahydrochloride (Y15), was used to study the effects of FAK inhibition on the adhesion and migration behaviors of vascular endothelial cells (VECs) and human hepatoblastoma cells. Furthermore, the time-dependent differences in proteins associated with the integrin-mediated FAK/ Rho GTPases signaling pathway within $2 \mathrm{~h}$ were examined. The results indicated that the inhibition of FAK significantly decreased the migration ability of VECs and human hepatoblastoma cells in a dose-dependent manner. Inhibition of FAK promoted cell detachment by decreasing the expression of focal adhesion components, and blocked cell motility by reducing the level of Rho GTPases. However, the expression of crucial proteins involved in integrin-induced signaling in two cell lines exhibited a time-dependent difference with increased duration of FAK inhibitor treatment, suggesting different mechanisms of FAK-mediated cell migration behavior. These results suggest that the mechanism underlying FAK-mediated adhesion and migration behavior differs among various cells,
\end{abstract}

Correspondence to: Professor Yang Shen or Professor Xiaoheng Liu, Institute of Biomedical Engineering, West China School of Basic Medical Sciences and Forensic Medicine, Sichuan University, 37 Guoxue Xiang, Chengdu, Sichuan 610041, P.R. China E-mail: shenyang24@126.com

E-mail: liuxiaohg@scu.edu.cn

Key words: cell adhesion, cell migration, focal adhesion kinase, tumor angiogenesis which is expected to provide evidence for future FAK therapy targeted against tumor angiogenesis.

\section{Introduction}

Tumor angiogenesis is crucial for cancer growth and metastasis, as the new blood vessels support progression of the primary tumor by providing oxygen and nutrients, which involves a complex interaction among multiple cells and cytokines (1). The interaction between tumor cells and vascular endothelial cells (VECs) participates in the process of tumor angiogenesis. The formation of new blood vessels is induced by pro-angiogenic factors secreted by tumor cells to facilitate the migration and proliferation of VECs, and VEC migration is a fundamental process of tumor angiogenesis (2). However, cancer cells degrade endothelial basement membrane and extracellular matrix (ECM) components in tumor blood vessels by releasing matrix metalloproteinases; subsequently, cancer cells migrate and invade into the circulation, ultimately forming new metastatic lesions in surrounding tissues (3). Therefore, preventing the migration of VECs and/or tumor cells may be a valuable new approach to cancer therapy by inhibiting tumor growth, invasion and metastasis.

Cell adhesion/migration is a complex and dynamic multistep process that involves a balance between assembly and disassembly of matrix-cell adhesion sites. Focal adhesion kinase (FAK) is a non-receptor tyrosine kinase that is overexpressed in several types of tumors. FAK regulates cell adhesion and migration signals in various cell lines, is involved in the engagement of integrin and assembly of focal adhesions (FA) through catalyzing several downstream signals, and mediates cell behavior. The integrin family of cell adhesion receptors are major cellular receptors of ECM, and they act as signaling centers orchestrating a network of signaling pathways that mediate cell adhesion and migration (4). The FA components, including paxillin and talin, recruit FAK to FA. The phosphorylation of paxillin specifically induces the recruitment of the cytoskeletal adapter protein vinculin to FA (5). FAK directly binds to the $\beta$ subunit of integrins, and its FAT domain binds to talin and paxillin. The initial autophosphorylation of Y397-FAK tyrosine may subsequently result in the phosphorylation of additional multiple tyrosine sites (Y-576, -577 and -925) (6). FAK also interacts with the 
p85 subunit of phosphatidylinositol 3-kinase (PI3K) and then stimulates AKT, also referred to as protein kinase B (PKB), which may regulate FAK indirectly through interaction with a joint partner protein that can bind to both FAK and AKT to form a triple complex $(7,8)$. FAK/PI3K- and Rho GTPase-mediated signaling is involved in signal integration and crosstalk during cell adhesion and migration. The Rho family of GTPases, including Rho, Rac and $\mathrm{Cdc} 42$, are crucial for regulating the formation of stress fibers, lamelipodia and filopodia, respectively, and control FA formation and various cell functions, such as cell adhesion, cell migration and changes in cell shape $(9,10)$.

Endothelial FAK is required for adult pathological tumor angiogenesis, and inhibition of FAK in both endothelial and cancer cells is considered to be a possible target for anti-angiogenic therapies. Endothelial FAK is required for tumor angiogenesis (11), and the link between FAK and cancer is supported by evidence of increased FAK expression in several different types of cancer (12-17). However, the changes in those crucial proteins associated with integrin-mediated FAK signaling, and whether FAK acts in the same manner in VECs and hepatoblastoma cells, remain poorly understood.

In the present study, the adhesion and migration behavior of VECs (EA.hy926) and the human hepatoblastoma cells HepG2 was examined following addition of a FAK inhibitor; the expression of crucial proteins in the integrin-mediated FAK signaling pathway was also investigated in order to determine whether inhibition of FAK may be used for the treatment of cancer, as well as that of other diseases, through inhibition of angiogenesis.

\section{Materials and methods}

Cell lines. In this study, due to their higher affinity for the tissue culture polystyrene without fibronectin or collagen precoating, the human vascular EC line EA.hy926 (Jiangsu Institute of Hematology, Suzhou, China) was used rather than original ECs. EA.hy926 cells are a hybridoma cell line between human umbilical vein eECs (HUVECs) and epithelioma A549 cells, and they retain most of the characteristics of HUVECs, including the expression of endothelial adhesion molecules and human factor VIII-related antigen (18), which has been previously identified in our laboratory. Hepatoblastoma is the most common pediatric malignant hepatic tumor worldwide. The human hepatoblastoma HepG2 cell line (Institute of Biochemistry and Cell Biology, Shanghai Institutes for Biological Sciences, Chinese Academy of Sciences, Shanghai, China) is one of the most extensively investigated in the literature, and was used as a representative cancer cell line in the present study.

Antibodies. Detailed information on primary antibodies is provided in Table I. The secondary fluorescein isothiocyanate (FITC)-conjugated goat anti-mouse immunoglobulin $\mathrm{G}(\operatorname{IgG})$ and PE-conjugated goat anti-rabbit IgG were purchased from Beijing Biosynthesis Biotechnology Co., Ltd. (Beijing, China). The BODIPY FL phallacidin (Invitrogen Life Technologies; Thermo Fisher Scientific, Carlsbad, CA, USA) was used for F-actin staining.

FAK inhibitor (Y15). The FAK inhibitor 1,2,4,5-benzenetetramine tetrahydrochloride (Y15) increases cell detachment and inhibits cell adhesion in a dose- and time-dependent manner, as observed and tested by Golubovskaya et al (19). In the present study, Y15 (Sigma-Aldrich; Merck KGaA, St. Louis, MO, USA) was used to investigate whether the migration and adhesion of EA.hy926 and HepG2 cells depend on FAK signaling, and to determine the time-dependent expression of crucial proteins in the integrin-induced FAK/Rho GTPases pathway.

First, Y15 at different concentrations (50, 100, 150, 200 and $250 \mu \mathrm{M}$ ) was added into 6-well polystyrene cell culture plates for cell migration analysis, and an appropriate concentration of the FAK inhibitor was determined for further examination.

Cell culture. EA.hy926 cells were cultured in RPMI-1640 nutrient mixture with $10 \%$ fetal bovine serum (FBS) (both from Gibco-BRL; Thermo Fisher Scientific, Grand Island, NY, USA), HAT supplement (Sigma-Aldrich; Merck KGaA), $100 \mathrm{U} / \mathrm{ml}$ penicillin and streptomycin (both from Beyotime Institute of Biotechnology, Shanghai, China), and grown at $37^{\circ} \mathrm{C}$ in $95 \%$ air and $5 \% \mathrm{CO}_{2}$. HepG2 cells were cultured in Dulbecco's modified Eagle's medium-high glucose (Gibco-BRL; Thermo Fisher Scientific) with $10 \%$ FBS, $100 \mathrm{U} / \mathrm{ml}$ penicillin and streptomycin, and grown at $37^{\circ} \mathrm{C}$ in $95 \%$ air and $5 \% \mathrm{CO}_{2}$.

Parallel cell migration-scratch wound assay. The scratch wound assay was used to investigate the migration ability of EA.hy926 and HepG2 cells in parallel directions. Cells were seeded on a culture dish, the bottom of which was previously marked with three parallel lines, and cells with $100 \%$ confluence were starved without serum overnight. A uniform scratch $(\sim 500 \mu \mathrm{m})$, perpendicular to the lines on the bottom of the dish, was then made in the monolayer with a plastic cell scraper to obtain three cross regions. The cell monolayer was washed three times with phosphate-buffered saline (PBS); Y15 was added to the serum-free medium and the three cross regions were photographed with a reflective upright biological microscope. Images of the wounds under culture were acquired and analyzed at 0,2 , 4,8 and $24 \mathrm{~h}$, the appropriate concentration of FAK inhibitor was determined, and detailed images of the wounds were captured at $0,5,10,30,60$ and 120 min under an inverted microscope.

Vertical cell migration-Transwell assay. Cell migration was further determined by the Transwell assay $(8-\mu \mathrm{m}$ pore size; BD Falcon ${ }^{\mathrm{TM}}$; BD Biosciences, Franklin Lakes, NJ, USA). EA.hy926 and HepG2 cells were cultured and adhered in the Transwell chamber for $4 \mathrm{~h}$, and were serum-starved overnight, followed by the addition of $50 \mu \mathrm{M}$ Y15 for $24 \mathrm{~h}$ at $37^{\circ} \mathrm{C}$ and $5 \% \mathrm{CO}_{2}$. The inner chamber of the Transwell unit was cleaned, and the migrated HepG2 cells on the bottom of the chamber were fixed by $4 \%$ paraformaldehyde for $10 \mathrm{~min}$ and stained with $0.1 \%$ crystal violet for $15 \mathrm{~min}$. Each step was followed by washing with PBS three times. The migrated cells were photographed at 5 different areas under an inverted phase contrast microscope (CK2; Olympus, Tokyo, Japan). The cell number of each group in one vision field was counted based on obtained optical images. At least three parallel experiments were performed, and data are presented as mean \pm standard deviation (SD).

Immunofluorescence staining. EA.hy926 and HepG2 cells were plated on small circular slides with $50 \%$ confluence and serum 
Table I. Detailed information on the antibodies used in the present study.

\begin{tabular}{|c|c|c|c|c|c|c|}
\hline Category & Antibody & Isotype & $\begin{array}{c}\text { Blocking } \\
\text { conditions } 1 \mathrm{~h} \\
\text { room temperature }\end{array}$ & $\begin{array}{l}\text { Primary Ab } \\
\text { incubation }\end{array}$ & Manufacturer & Cat. nos \\
\hline \multirow[t]{5}{*}{ Integrins } & $\alpha 2(\mathrm{C}-9)$ & Mouse mAb & $\begin{array}{l}5 \% \text { non-fat dry } \\
\text { milk in PBS }\end{array}$ & $\begin{array}{l}\text { Overnight at } 4^{\circ} \mathrm{C}, \\
1: 200 \text { dilution }\end{array}$ & $\begin{array}{l}\text { Santa Cruz Biotechnology, } \\
\text { Inc., Santa Cruz, CA, USA }\end{array}$ & sc-74466 \\
\hline & $\alpha 5(\mathrm{~A}-11)$ & Mouse mAb & $\begin{array}{l}5 \% \text { non-fat dry } \\
\text { milk in PBS }\end{array}$ & $\begin{array}{l}\text { Overnight at } 4^{\circ} \mathrm{C}, \\
1: 200 \text { dilution }\end{array}$ & & sc-166665 \\
\hline & $\alpha \mathrm{V}(\mathrm{H}-2)$ & Mouse mAb & $\begin{array}{l}5 \% \text { non-fat dry } \\
\text { milk in PBS }\end{array}$ & $\begin{array}{l}\text { Overnight at } 4^{\circ} \mathrm{C}, \\
1: 200 \text { dilution }\end{array}$ & & sc-376156 \\
\hline & $\beta 1(\mathrm{~A}-4)$ & Mouse mAb & $\begin{array}{l}5 \% \text { non-fat dry } \\
\text { milk in PBS }\end{array}$ & $\begin{array}{l}\text { Overnight at } 4^{\circ} \mathrm{C}, \\
1: 200 \text { dilution }\end{array}$ & & sc-374429 \\
\hline & $\beta 3(\mathrm{~B}-7)$ & Mouse mAb & $\begin{array}{l}5 \% \text { non-fat dry } \\
\text { milk in PBS }\end{array}$ & $\begin{array}{l}\text { Overnight at } 4^{\circ} \mathrm{C} \text {, } \\
1: 200 \text { dilution }\end{array}$ & & sc-46655 \\
\hline \multirow[t]{5}{*}{$\begin{array}{l}\text { FA } \\
\text { components }\end{array}$} & Talin (8D4) & Mouse mAb & $\begin{array}{l}5 \% \text { non-fat dry } \\
\text { milk in PBS }\end{array}$ & $\begin{array}{l}\text { Overnight at } 4^{\circ} \mathrm{C}, \\
1: 200 \text { dilution }\end{array}$ & $\begin{array}{l}\text { Santa Cruz Biotechnology, } \\
\text { Inc., Santa Cruz, CA, USA }\end{array}$ & sc-59881 \\
\hline & Paxillin (D-9) & Mouse mAb & $\begin{array}{l}5 \% \text { non-fat dry } \\
\text { milk in PBS }\end{array}$ & $\begin{array}{l}\text { Overnight at } 4^{\circ} \mathrm{C}, \\
1: 200 \text { dilution }\end{array}$ & & sc-365174 \\
\hline & Vinculin (G-11) & Mouse mAb & $\begin{array}{l}5 \% \text { non-fat dry } \\
\text { milk in PBS }\end{array}$ & $\begin{array}{l}\text { Overnight at } 4^{\circ} \mathrm{C}, \\
1: 200 \text { dilution }\end{array}$ & & sc-55465 \\
\hline & $\alpha$-actinin $(\mathrm{H}-2)$ & Mouse mAb & $\begin{array}{l}5 \% \text { non-fat dry } \\
\text { milk in PBS }\end{array}$ & $\begin{array}{l}\text { Overnight at } 4^{\circ} \mathrm{C}, \\
1: 200 \text { dilution }\end{array}$ & & sc-17829 \\
\hline & Zyxin (H-200) & Rabbit pAb & $\begin{array}{l}5 \% \text { non-fat dry } \\
\text { milk in PBS }\end{array}$ & $\begin{array}{l}\text { Overnight at } 4^{\circ} \mathrm{C}, \\
1: 200 \text { dilution }\end{array}$ & & sc-15338 \\
\hline \multirow[t]{2}{*}{ pFAK } & FAK (A-17) & Rabbit pAb & $\begin{array}{l}5 \% \text { non-fat dry } \\
\text { milk in PBS }\end{array}$ & $\begin{array}{l}\text { Overnight at } 4^{\circ} \mathrm{C}, \\
1: 200 \text { dilution }\end{array}$ & $\begin{array}{l}\text { Santa Cruz Biotechnology, } \\
\text { Inc., Santa Cruz, CA, USA }\end{array}$ & sc-557 \\
\hline & pFAK (2D11) & Mouse mAb & $3 \% \mathrm{BSA}$ in $\mathrm{PBS}$ & $\begin{array}{l}\text { Overnight at } 4^{\circ} \mathrm{C} \text {, } \\
1: 200 \text { dilution }\end{array}$ & & sc-81493 \\
\hline \multirow[t]{3}{*}{ PI3K/AKT } & PI3K-C2 $\beta$ (16L9) & Mouse mAb & $\begin{array}{l}5 \% \text { non-fat dry } \\
\text { milk in PBS }\end{array}$ & $\begin{array}{l}\text { Overnight at } 4^{\circ} \mathrm{C} \text {, } \\
1: 200 \text { dilution }\end{array}$ & $\begin{array}{l}\text { Santa Cruz Biotechnology, } \\
\text { Inc., Santa Cruz, CA, USA }\end{array}$ & sc-100407 \\
\hline & AKT1 (B-1) & Mouse mAb & $\begin{array}{l}5 \% \text { non-fat dry } \\
\text { milk in PBS }\end{array}$ & $\begin{array}{l}\text { Overnight at } 4^{\circ} \mathrm{C}, \\
\text { 1:200 dilution }\end{array}$ & & sc-5298 \\
\hline & pAKT1 (Thr308) & Rabbit pAb & $3 \% \mathrm{BSA}$ in $\mathrm{PBS}$ & $\begin{array}{l}\text { Overnight at } 4^{\circ} \mathrm{C} \text {, } \\
1: 200 \text { dilution }\end{array}$ & & sc-135650 \\
\hline \multirow[t]{4}{*}{$\begin{array}{l}\text { Rho } \\
\text { GTPases }\end{array}$} & Rac1 (C-11) & Rabbit pAb & $\begin{array}{l}5 \% \text { non-fat dry } \\
\text { milk in PBS }\end{array}$ & $\begin{array}{l}\text { Overnight at } 4^{\circ} \mathrm{C}, \\
1: 200 \text { dilution }\end{array}$ & $\begin{array}{l}\text { Santa Cruz Biotechnology, } \\
\text { Inc., Santa Cruz, CA, USA }\end{array}$ & sc-95 \\
\hline & pRac1 (Ser71) & Rabbit pAb & $3 \% \mathrm{BSA}$ in $\mathrm{PBS}$ & $\begin{array}{l}\text { Overnight at } 4^{\circ} \mathrm{C}, \\
1: 200 \text { dilution }\end{array}$ & & sc-12924-R \\
\hline & RhoA (26C4) & Mouse mAb & $\begin{array}{l}5 \% \text { non-fat dry } \\
\text { milk in PBS }\end{array}$ & $\begin{array}{l}\text { Overnight at } 4^{\circ} \mathrm{C}, \\
1: 200 \text { dilution }\end{array}$ & & sc-418 \\
\hline & $\mathrm{Cdc} 42$ & Rabbit mAb & $\begin{array}{l}5 \% \text { non-fat dry } \\
\text { milk in PBS }\end{array}$ & $\begin{array}{l}\text { Overnight at } 4^{\circ} \mathrm{C}, \\
1: 100 \text { dilution }\end{array}$ & Abcam $^{\circledR}$, Cambridge, UK & ab64533 \\
\hline
\end{tabular}

FAK, focal adhesion kinase; PI3K, phosphatidylinositol 3-kinase; PBS, phosphate-buffered saline; BSA, bovine serum albumin.

starvation overnight, and were incubated with FAK inhibitor $(50 \mu \mathrm{M})$ for $5 \mathrm{~min}$ or $2 \mathrm{~h}$. The cells were then washed twice with PBS for 8 min each time, fixed with $4 \%$ paraformaldehyde in PBS for $15 \mathrm{~min}$, washed three times with PBS for 5 min each time, permeabilized for 5 min with $1 \%$ (v/v) Triton X-100, and washed three times with PBS for 5 min each time. Cells were pre-incubated with $1 \%$ bovine serum albumin (BSA) in PBS for $15 \mathrm{~min}$ to decrease non-specific antibody binding, and washed for $30 \mathrm{sec}$ to $1 \mathrm{~min}$ with PBS. Primary antibody incubation was performed at $4^{\circ} \mathrm{C}$ overnight, the slides were washed for $5 \mathrm{~min}$ with PBS, further incubated for $90 \mathrm{~min}$ in FITC-conjugated goat anti-mouse antibody and PE-conjugated goat anti-rabbit antibody, and then incubated with 4',6-diamidino-2-phenylindole (DAPI) for $30 \mathrm{~min}$ to stain the nuclei. The samples were sealed by $10 \%$ glycerol, protected from light and examined under a laser scanning confocal microscope.

Western blot analysis of proteins associated with FAK signaling pathways. The western blot assays followed standard protocols. Briefly, following treatment with the FAK inhibitor for 0, 5, 10, 30, 60 and 120 min, EA.hy926 and HepG2 cells were washed three times with PBS and lysed by $200 \mu \mathrm{l}$ cell lysis solution (Beyotime Institute of Biotechnology). The RIPA lysis buffer includes phosphatase inhibitor $\left(\mathrm{Na}_{3} \mathrm{VO}_{4}\right)$, protease inhibitor 
mixtures (BestBio Biotechnology Co., Ltd., Shanghai, China) and phenylmethanesulfonyl fluoride (PMSF; Amresco, LLC, Solon, OH, USA), at a ratio of 100 (RIPA):1 (phosphatase inhibitor):1 (protease inhibitor mixtures):1 (PMSF). The total proteins were collected and centrifuged at $10,000 \mathrm{x} \mathrm{g} / \mathrm{min}$ at $4^{\circ} \mathrm{C}$ for $10 \mathrm{~min}$ and the supernatant was collected. Following a protein concentration assay by an ultraviolet spectrophotometer using the bicinchoninic acid protein assay kit, the proteins $(20 \mu \mathrm{g} /$ lane $)$ were separated by $10 \%$ SDS-PAGE and transferred to a PVDF membrane. BSA (5\%) powder in Tris-buffered saline with Tween-20 (TBST) was used to block non-specific binding for $2 \mathrm{~h}$ at $37^{\circ} \mathrm{C}$. Incubation with primary antibodies against integrin $\alpha 2, \alpha 5, \alpha \mathrm{V}, \beta 1, \beta 3$, vinculin, paxillin, talin, pFAK, PI3K, pAKT, pRhoA, pRac1 and Cdc42 overnight at $4^{\circ} \mathrm{C}$ was followed by incubation with horseradish peroxidase-conjugated goat anti-mouse or goat anti-rabbit antibody for $1 \mathrm{~h}$ at $37^{\circ} \mathrm{C}$. After washing with TBST, targeted proteins were detected using enhanced chemiluminescence (Beyotime Institute of Biotechnology). Images of bands were determined using Molecular Imager ${ }^{\circledR}$ ChemiDoc $^{\text {TM }}$ XRS+ with Image $\mathrm{Lab}^{\mathrm{TM}}$ software (Bio-Rad Laboratories, Inc., Hercules, CA, USA).

Statistical analyses. Data obtained from the present study are expressed as mean \pm SD from at least three independent experiments. To reveal differences among the groups, one-way analysis of variance followed by Tukey's test was used. The differences were considered significant at $\mathrm{P}<0.05$.

\section{Results}

Effect of FAK inhibitor on cell migration at various concentrations and durations. The effect of FAK inhibitor at various concentrations (50-250 $\mu \mathrm{M})$ on the migration behavior of EA.hy926 and HepG2 cells was examined using scratch wound assays (Fig. 1A and C), and the results were calculated as shown in Fig. 1B and D. It may be seen from Fig. 1 that the FAK inhibitor significantly inhibited the migration of ECs, as well as that of tumor cells. Under high concentrations of Y15 $(>150 \mu \mathrm{M})$, the migration distance of ECs at $2 \mathrm{~h}$ differed significantly from that of control cells (cells without addition of Y15) and low concentration groups (50 and $100 \mu \mathrm{M})$. The migration distance at $24 \mathrm{~h}$ of all groups treated with FAK inhibitor differed significantly from that of control cells. As shown in Fig. 1A, the ECs in the control group reached a $\sim 90 \%$ confluence at $24 \mathrm{~h}$, while $\mathrm{Y} 15$ prevented EC migration. In HepG2 cells, the migration distance in all Y15-treated groups differed significantly from that of control cells throughout the duration of the assay (from the initial 2 to $24 \mathrm{~h}$ ). However, a confluence of only $50 \%$ was observed in the control group at $24 \mathrm{~h}$ due to the weakened motility of HepG2 cells. The statistical results demonstrated that Y15 significantly inhibited cell motility in a dose-dependent manner (Fig. 1B and D).

Based on the previous results, $50 \mu \mathrm{M}$ Y15 was selected to further investigate its inhibitory effect on cell migration by the Transwell assay. It was observed that, with FAK inhibition for $24 \mathrm{~h}$, the migrating numbers of both endothelial EA.hy 926 cells and HepG2 cells decreased significantly compared with the control group $(\mathrm{P}<0.05)$, suggesting that $\mathrm{Y} 15$ suppressed migration in the two cell lines (Fig. 2A and B). Furthermore,
$50 \mu \mathrm{M}$ Y15 was also used to examine its inhibitory effect on parallel cell migration by the scratch wound assay within $2 \mathrm{~h}$. The local changes of migrating cells are described in Fig. 2C and D. Migrating cells were clearly observed in the control group (Fig. 2C and D, white arrows) after $120 \mathrm{~min}$, but could hardly be identified in the $50-\mu \mathrm{M}$ group of EA.hy926 and HepG 2 cells. Therefore, migration in the two types of cells was distinctly inhibited by $50 \mu \mathrm{M}$ Y 15 .

Effect of FAK inhibition on the cytoskeleton. Furthermore, changes in the localization of F-actin were examined in order to determine the effect of FAK inhibition on cell adhesion. Cell adhesion is closely coupled with the protrusions of the leading edge of migrating cells (filopodia and lamellipodia). It was observed from confocal immunofluorescence images of F-actin staining that the formation of filopodia was markedly impaired by FAK in EA.hy926 (Fig. 3A) as well as in HepG2 cells (Fig. 3B). In the control groups of the two cell lines (Fig. 3), all spreading cells displayed polymerized F-actin in the protrusions, and more obvious spike-like filopodia and intercellular filaments were observed among cells. However, in the treated groups (2-h FAK inhibition; right panels in Fig. 3), endothelial as well as hepatoblastoma cells exhibited decreased cell spreading areas, and fewer filopodia were present at the edge of any single cell. In HepG2 cells (Fig. 3B), in particular, it was observed that the cells became round and lost their filopodia and lamellipodia, whereas cell adhesion was evidently inhibited. However, the enlarged images revealed a distinct filamentous stress fiber structure (Fig. 3, yellow arrows) in single cells following addition of Y15 for $2 \mathrm{~h}$, while there was no ordered stress fiber structure found in the control group (without Y15 treatment). These results suggested that inhibition of FAK reduced the adhesion sites between the cells and the matrix, which may result in promotion of cell detachment and inhibition of cell adhesion. Furthermore, the inhibition of FAK induced retraction of protrusive filopodia and lamellipodia, which was responsible for actin polymerization and stress fiber formation in the retractile cell bodies.

Expression and distribution of FAK with the addition of the FAK inhibitor Y15. The initial autophosphorylation of FAK at Y397 results in phosphorylation of additional multiple tyrosine sites (Y-576, -577 and -925) in FAK, which regulate a number of cell functions, including cell adhesion and cell migration. Therefore, the effect of $50 \mu \mathrm{M}$ Y15 on total phosphorylation and phosphorylation at the Y397 site of FAK within $2 \mathrm{~h}$ was first examined by western blot analysis (Fig. 4A and B), and the relative quantification of the phosphorylated FAK (pFAK) level against total FAK (tFAK) expression is presented in Fig. 4C and D in EA.hy926 and HepG2 cells, respectively. Increased duration of FAK inhibition resulted in a significant decrease of the total and phosphorylated FAK level in ECs (Fig. 4A). tFAK exhibited a gradual reduction tendency. However, pFAK decreased initially, followed by a transient increase over 10-30 min, suggesting that inhibition of FAK may activate compensatory effects by other signaling molecules. The statistical result of the relative quantification of the pFAK level in tFAK (Fig. 4C) revealed that the pFAK/tFAK ratio at 5 and 10 min was significantly decreased compared with the control $(\mathrm{P}<0.05)$; subsequently, the increased $\mathrm{pFAK} / \mathrm{tFAK}$ 


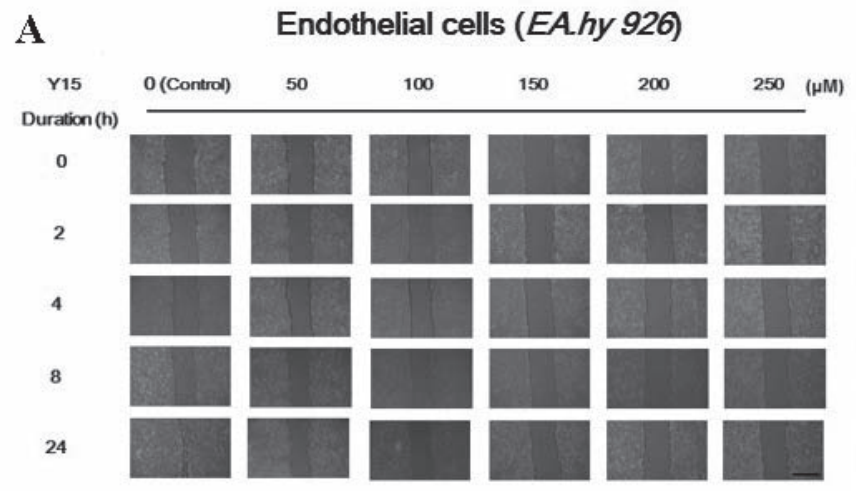

\section{C}

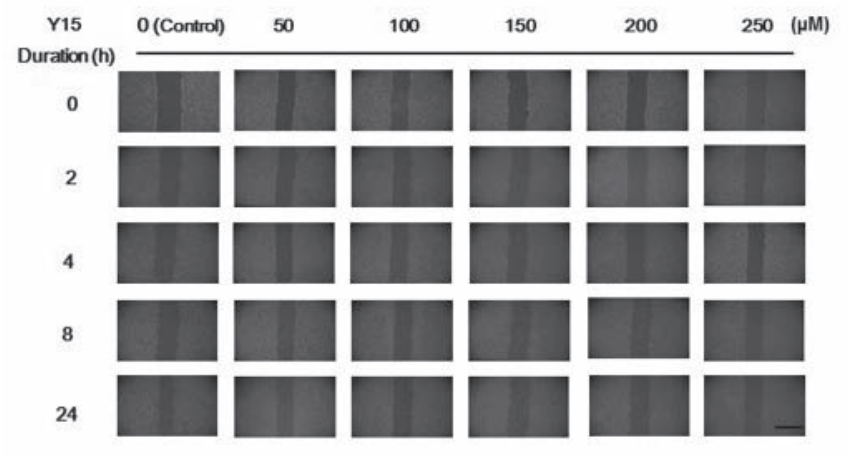

B

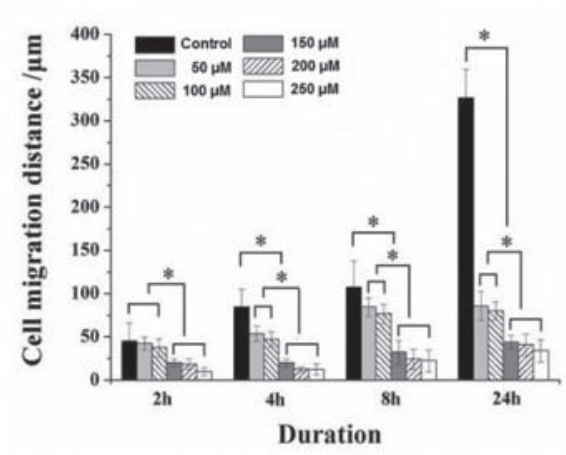

D

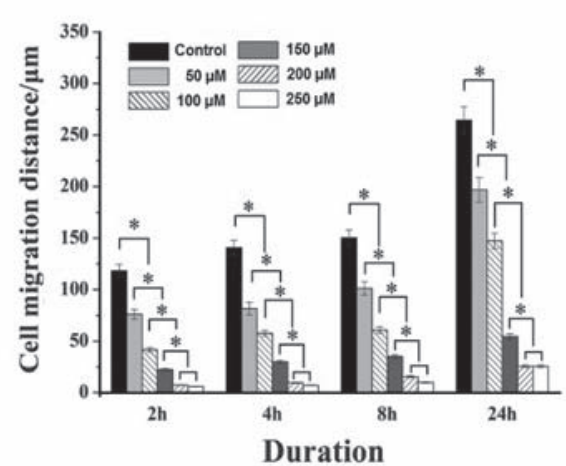

Figure 1. Inhibition of focal adhesion kinase (FAK) blocked endothelial and hepatoblastoma cell migration in a concentration-dependent manner. Effect of the FAK inhibitor Y15 at increasing concentrations on the migration of (A) endothelial cells and (C) hepatoblastoma cells; scale bar, $500 \mu \mathrm{m}$. Statistical analysis of the mean cell migration distance of (B) endothelial cells and (D) hepatoblastoma cells in three independent experiments. "P<0.05 denotes a statistically significant difference. The mean \pm standard error of three independent experiments are shown.

ratio at 30 min was significantly different compared with that at 5 and 10 min $(\mathrm{P}<0.05)$, indicating a temporarily higher expression of pFAK at 10-30 min with a continuous decline of tFAK. The pFAK/tFAK ratio at 120 min was relatively higher, suggesting a weak effect of FAK inhibition on pFAK, but a strong effect on tFAK. By contrast, tFAK in HCC cells was greatly inhibited at the initial stage, both tFAK and pFAK increased at 10-30 min, and then decreased at $120 \mathrm{~min}$. Initially, tFAK sharply decreased, but pFAK was not inhibited; therefore, the relative $\mathrm{pFAK} / \mathrm{tFAK}$ ratio at 5 and $10 \mathrm{~min}$ was significantly increased compared with the control (Fig. 4D; $\mathrm{P}<0.05$ ), and the ratio decreased significantly at 30 min compared with that at 5 and $10 \mathrm{~min}$ and at 60 and $120 \mathrm{~min}(\mathrm{P}<0.05)$, indicating that the expression of pFAK was not inhibited initially with the changes in tFAK in HCC cells. The results also indicated that inhibition of FAK in various cell lines exerted different time-dependent effects on tFAK and pFAK expression.

Furthermore, the distribution of tFAK and pFAK at $5 \mathrm{~min}$ and $2 \mathrm{~h}$ was examined by double immunofluorescence staining (Fig. 4E). The expression levels of tFAK and pFAK were consistent with the results of the western blot analysis. With a 2-h inhibition of FAK, the levels of tFAK and pFAK decreased in both endothelial and hepatoblastoma cells. It was observed that pFAK expression was significantly inhibited in
ECs; in addition, the intensity of tFAK was also reduced. The expression level of tFAK in hepatoblastoma cells decreased, and pFAK exhibited a lower intensity after $5 \mathrm{~min}$ of treatment with the inhibitor. When combining the distribution of FAK and its phosphorylated counterpart, pFAK (green) is clearly more highly expressed at the leading edge of the cell in the control groups compared with the groups undergoing FAK inhibition for $2 \mathrm{~h}$ (Fig. 4E and F). Compared with the control groups of both cell lines, weak green fluorescence (pFAK) was observed at the leading edge of the cells, suggesting that the FAK inhibitor used in the present study clearly inhibited the expression of pFAK and also decreased the level of tFAK. In conclusion, the results demonstrated that the response time of FAK differs among various cells treated with FAK inhibitor, resulting in time-dependent differences in protein expression in the entire signaling cascade. Furthermore, the inhibitory effect of FAK on the integrin-induced signaling pathway involved in cell adhesion and migration was further investigated.

Time-dependent expression of integrins with inhibition of $F A K$. Integrins are transmembrane ECM receptors containing $\alpha$ and $\beta$ subunits that bind to cytoskeletal proteins and transduce signals from extracellular stimuli to intracellular events (20). It has been reported that pFAK regulates cell 
$\mathbf{A}$

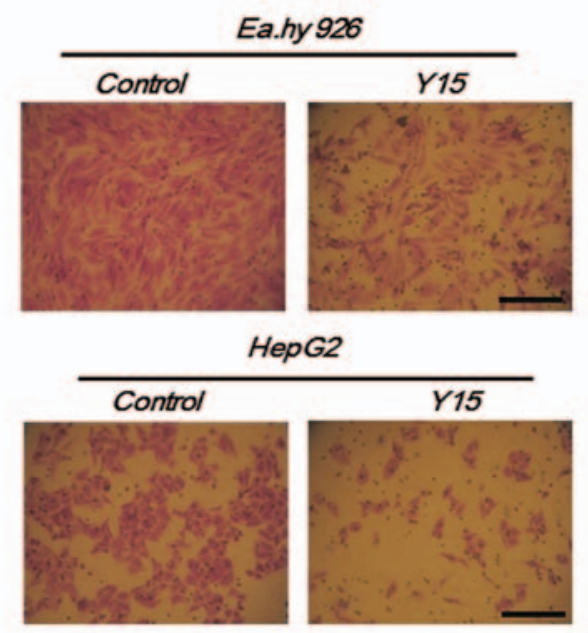

C

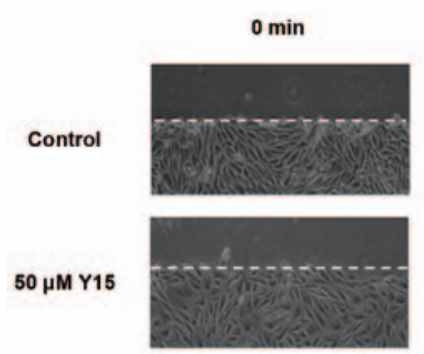

Ea.hy 926 cells

$120 \mathrm{~min}$
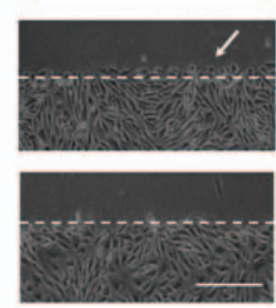

B

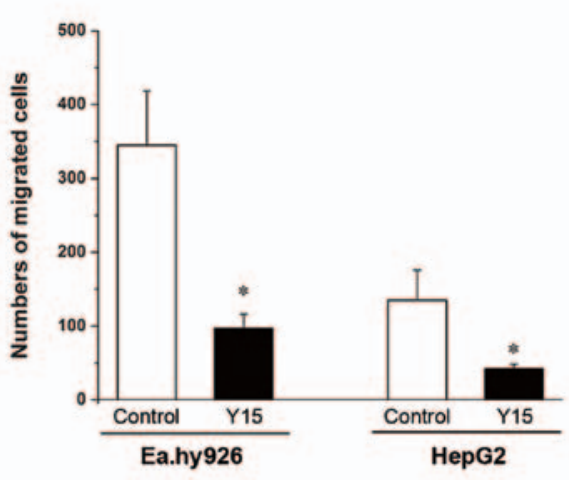

HepG2 cells

$0 \mathrm{~min}$
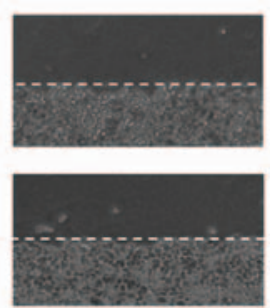

\section{$120 \mathrm{~min}$}
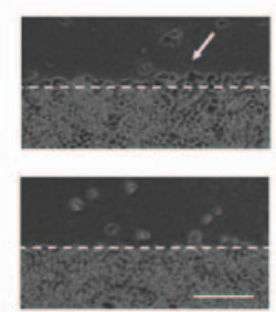

Figure 2. Detailed images of focal adhesion kinase (FAK) inhibitor (Y15) inhibition of cell migration using (A) Transwell assay for $24 \mathrm{~h}$ and (C) scratch wound assays within $2 \mathrm{~h}$. (A) Migrating EA.hy 926 and HepG2 cells with or without $50 \mu \mathrm{mol} / \mathrm{ml} \mathrm{Y15} \mathrm{for} 24 \mathrm{~h}$ by Transwell assay (x10 magnification); scale bar, $100 \mu \mathrm{m}$. (B) Statistical analysis of migrating cells numbers in one field of vision." $\mathrm{P}<0.05$ vs. controls. The mean \pm standard error of three independent experiments are shown. (C) Detailed images of FAK inhibition with $50 \mu \mathrm{M}$ Y15 blocking cell migration within $2 \mathrm{~h}$. Cell migration of EA.hy926 and HepG2 cells with FAK inhibition within $2 \mathrm{~h}$ by scratch wound assay. The dotted lines denote the baseline of the scratch wound; the white arrows indicate the visible migrated cells in the two control groups; scale bar, $100 \mu \mathrm{m}$.

A EA.hy926 cells

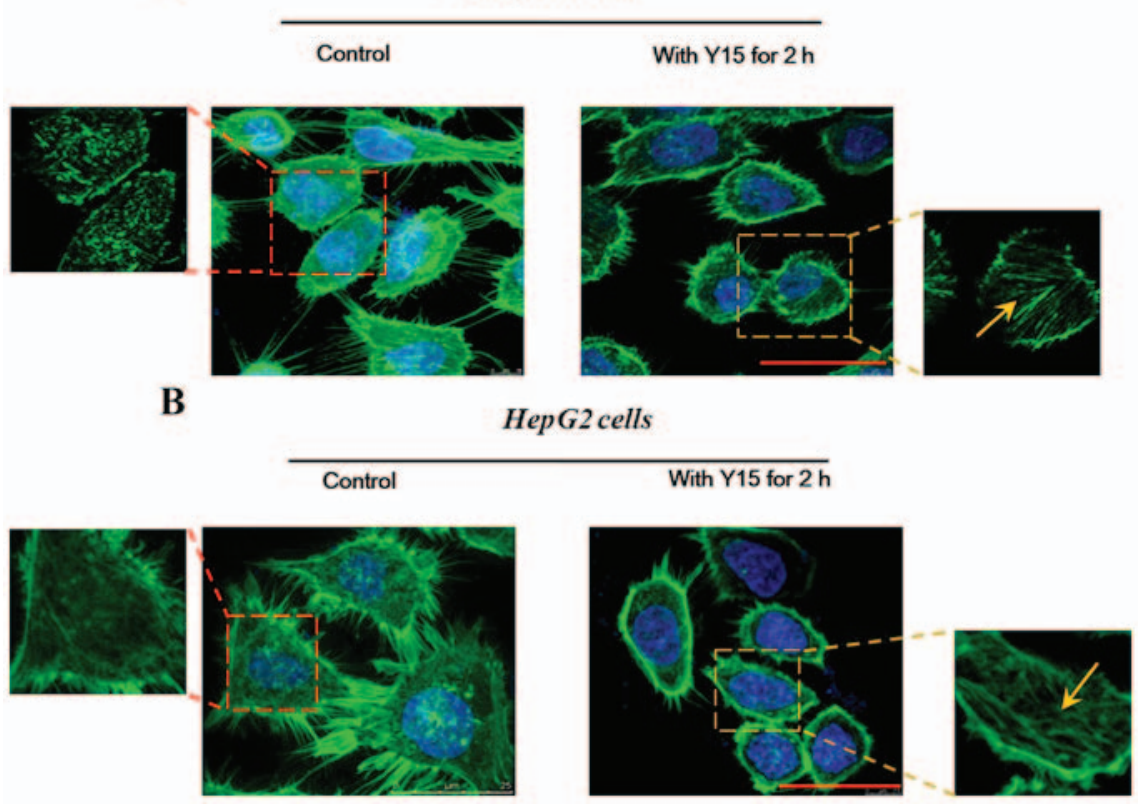

Figure 3. Effect of treatment with $50 \mu \mathrm{M}$ focal adhesion kinase (FAK) inhibitor (Y15) on the distribution of F-actin in Ea.hy926 and HepG2 cells. Confocal immunofluorescence images of (A) EA.hy926 and (B) HepG2 cells, showing changes in the localization of F-actin (green, F-actin; blue, nucleus) in response to $50 \mu \mathrm{M} \mathrm{Y} 15$ for $2 \mathrm{~h}$; scale bar, $20 \mu \mathrm{m}$. The designated region indicated by the red square frames was enlarged to show the detailed fiber structure in the cell body. Inhibition of FAK induced retraction of filopodia and lamellipodia in the cell protrusions, resulting in formation of stress fiber structures (yellow arrows) in the cell bodies. 
$\mathbf{A}$

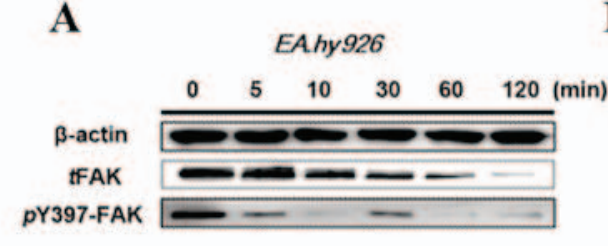

C

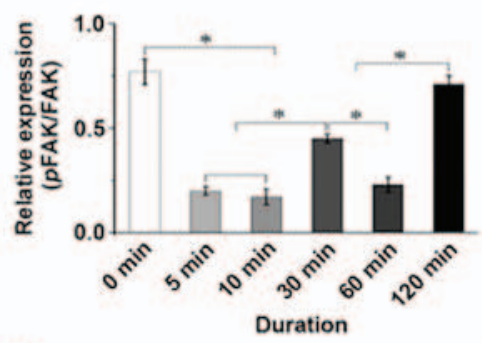

$\mathbf{E}$

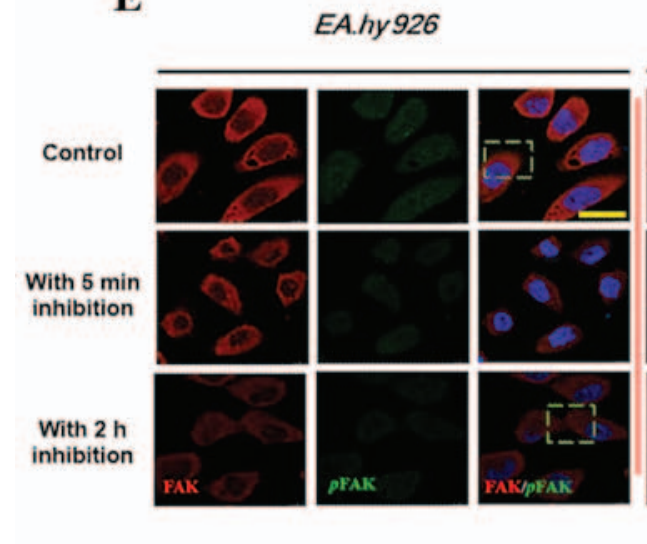

F
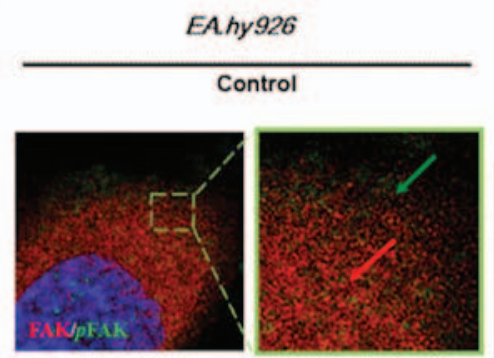

With $2 \mathrm{~h}$ inhibition
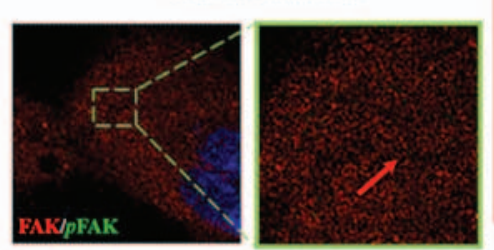

B

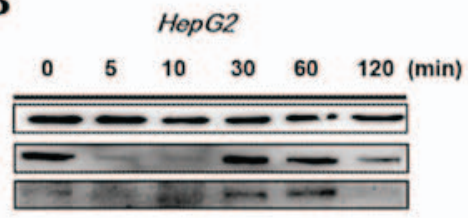

D

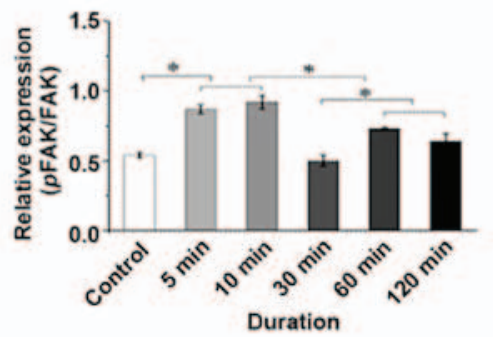

HepG2
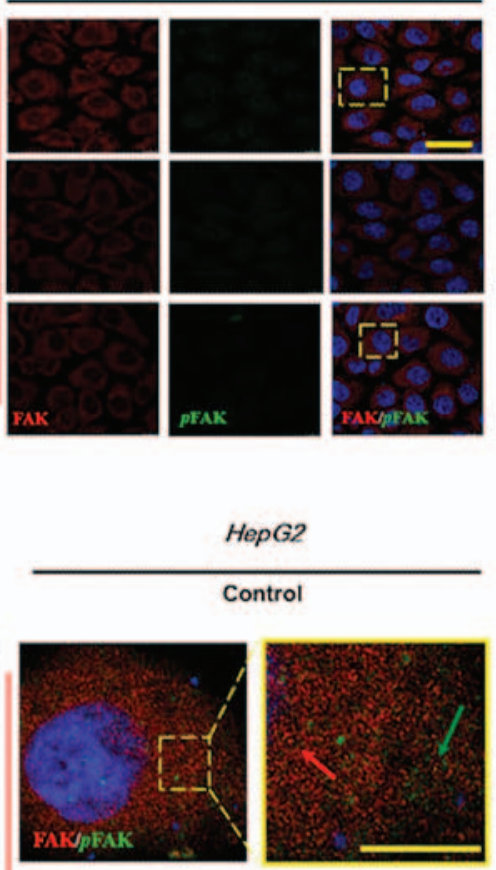

With $2 \mathrm{~h}$ inhibition
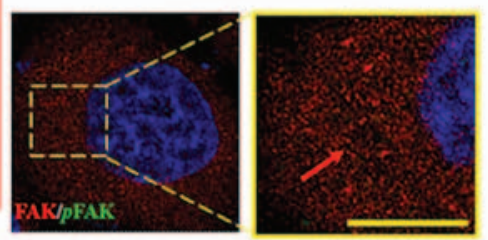

Figure 4. Expression level of total focal adhesion kinase (tFAK) and phosphorylated FAK (pFAK) with inhibition of FAK. (A and B) Time-dependent effect of the FAK inhibitor Y15 on the expression of tFAK and pFAK in endothelial cells and hepatoblastoma cells, respectively, within $2 \mathrm{~h}$. Quantification of pFAK in tFAK expression by image analysis of the western blot bands in (C) endothelial cells and (D) hepatoblastoma cells. Values represent the mean \pm standard deviation, $n=4{ }^{*} \mathrm{P}<0.05$ denotes a statistically significant difference compared with the other groups. (E) Double-labeled immunofluorescence analyzed the effects of distribution and expression of pFAK (green) and tFAK (red) proteins with inhibition of FAK after 5 min and 2 h (blue, DAPI stained nucleus); scale bar, $20 \mu \mathrm{m}$. (F) Enlarged images of designated regions, labeled by white square frames in (E); the green arrows indicate clear distribution of pFAK at the leading edge of the cells, while FAK with red fluorescence occupied the whole cytoplasm with 2 h FAK inhibition. A lower degree of green fluorescence may be observed at the cell periphery; scale bar, $2.5 \mu \mathrm{m}$.

adhesion and migration via binding activated integrin (16). In the present study, the expression levels of integrin $\alpha 2, \alpha 5, \alpha \mathrm{V}, \beta 1$ and $\beta 3$ subunits in response to FAK inhibition were investigated. It was observed that, as in EA.hy926 cells, integrin $\alpha 2$ and $\beta 3$ significantly decreased at 5-10 min with inhibition of FAK, and were restored to a higher level at 10-30 min, consistently with the recovery of the pFAK level at $10-30 \mathrm{~min}$; the $\beta 1$ subunit exhibited a stronger expression at 10-30 min; a gradually 
A

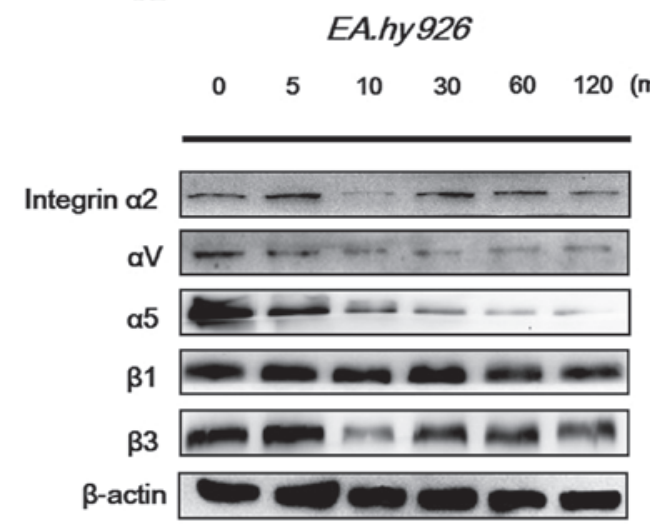

C

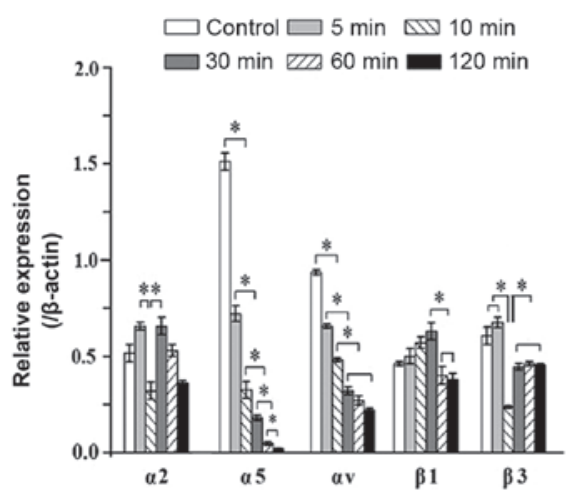

B

HepG2

$\begin{array}{lllllll}0 & 5 & 10 & 30 & 60 & 120 & (\min )\end{array}$

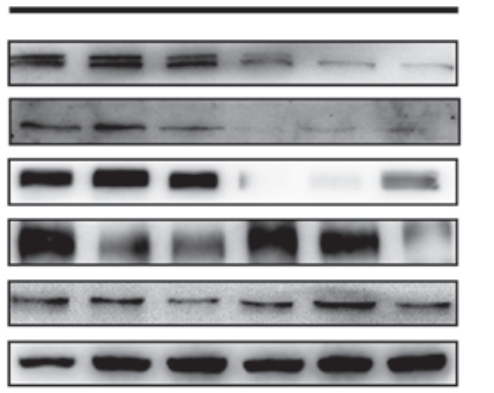

D

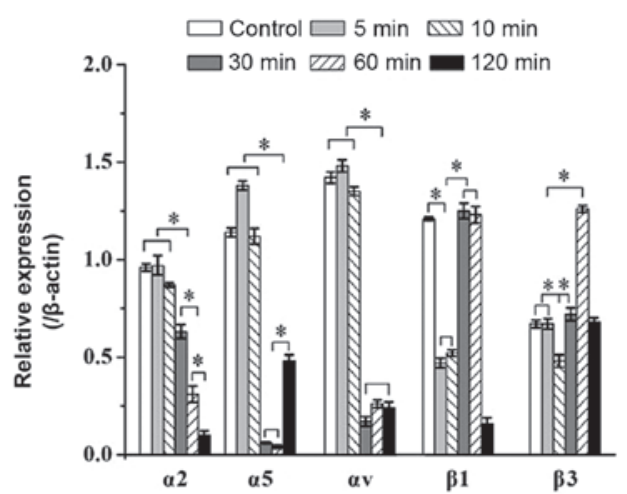

Figure 5. Inhibition of focal adhesion kinase (FAK) regulates the changes in the expression of integrin $\alpha$ and $\beta$ subunits in endothelial EA.hy926 and hepatoblastoma HepG2 cells. Expression level of integrins $\alpha 2, \alpha 5, \alpha \mathrm{V}, \beta 1$ and $\beta 3$ with FAK inhibitor treatment within $2 \mathrm{~h}$ in (A) endothelial cells and (B) hepatoblastoma cells. (C and D) Quantification of each integrin subunit expression level by image analysis of the western blot bands in (A and B). The expression level of $\beta$-actin in each group was used as an internal control, and the relative expressions of integrins were calculated. Data are presented as means \pm standard error of the mean from three independent experiments. " $\mathrm{P}<0.05$ denotes statistically significant differences.

weakened expression level of the $\alpha 5$ subunit was associated with increasing duration of Y15 treatment, whereas the expression of $\alpha \mathrm{V}$ exhibited a gradual decrease within $30 \mathrm{~min}$ and then remained stable (Fig. 5A and C). In HepG2 cells, $\beta 3$ exhibited a similar tendency to that in EA.hy926 cells within $60 \mathrm{~min}$, but exhibited a sharp increase at $1 \mathrm{~h}$, while the expression of $\alpha 2$ was gradually downregulated after $30 \mathrm{~min}$. The expression of $\alpha 5$ decreased sharply after $10 \mathrm{~min}$, but appeared to recover after $2 \mathrm{~h}$. The expression of $\alpha \mathrm{V}$ exhibited an acute decrease at $30 \mathrm{~min}$, and then remained stable, similar to ECs (Fig. 5B and D). Of note, with inhibition of FAK within $2 \mathrm{~h}$, the expression of the $\beta 1$ subunit appeared to be correlated with the level of tFAK in HepG2 cells (decreased initially at 5 min, was upregulated at 10-30 min, and reached a maximum level at $1 \mathrm{~h}$ ). Since FAK directly and indirectly binds to the $\beta$ tails of integrins, these results suggest that inhibition of FAK initiated a feedback signal to upstream events and decreased the expression of integrins, blocked integrin-induced loss of clustering and resulted in cell detachment. However, the responses of integrin subunits in various cell lines with FAK inhibition were different.

Expression of FA components with FAK inhibition. Integrins bind to the intracellular actin cytoskeleton through a complex network of regulatory proteins referred to as FA. The FA complex consists of several proteins, such as talin, vinculin and paxillin, and is located at the cytosolic face of the cell membrane. As a ligand of $\beta$ integrin cytoplasmic domains, talin plays a key role in the first step of focal complex formation following initial integrin engagement, and talin degradation plays a crucial role in FA turnover (4). The integrin-binding proteins paxillin and talin recruit FAK and vinculin to focal contacts. Vinculin, as a binding partner of talin, promotes and stabilizes initial integrin clustering, which may promote cell spreading by mechanically coupling integrins with the cytoskeleton, with the migration velocity of cells lacking vinculin being twice that of wild-type cells (21). Zyxin is a zinc-binding phosphoprotein that concentrates at FAs and along the actin cytoskeleton, and $\alpha$-actinin is an actin-binding protein that binds actin to the membrane. The assembly of these cytoskeletal proteins form actin-rich structures of FA, and contribute to support stable cell-matrix adhesion. Therefore, the time-dependent changes in the levels of talin, vinculin, paxillin, zyxin and $\alpha$-actinin with inhibition of FAK within $2 \mathrm{~h}$ were investigated.

As seen in Fig. 6A, the vinculin level in ECs exhibited no significant differences with increased duration of Y15 treatment. However, the expression of talin and paxillin in ECs showed an identical tendency (decreased at 5-10 min, but was upregulated at $30 \mathrm{~min}$ and subsequently decreased). The expression of zyxin 
A

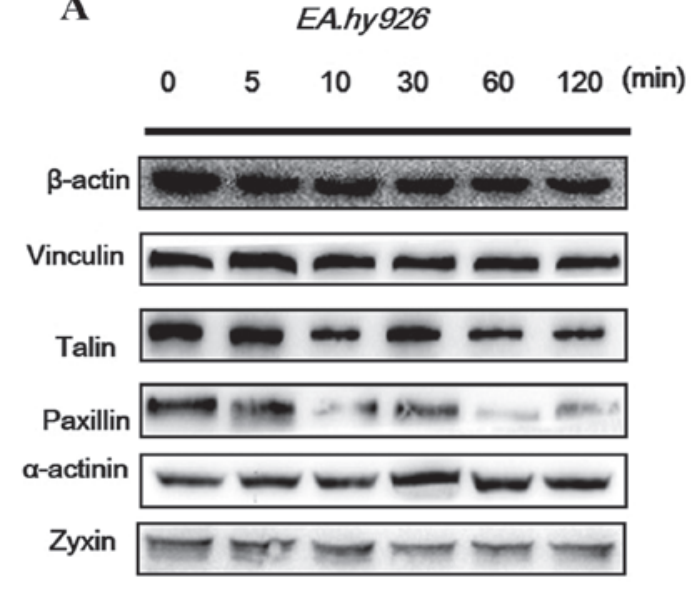

C $\square$ Control $\square 5 \mathrm{~min} \square 10 \mathrm{~min}$ $\square 30 \mathrm{~min} \square 60 \mathrm{~min}=120 \mathrm{~min}$

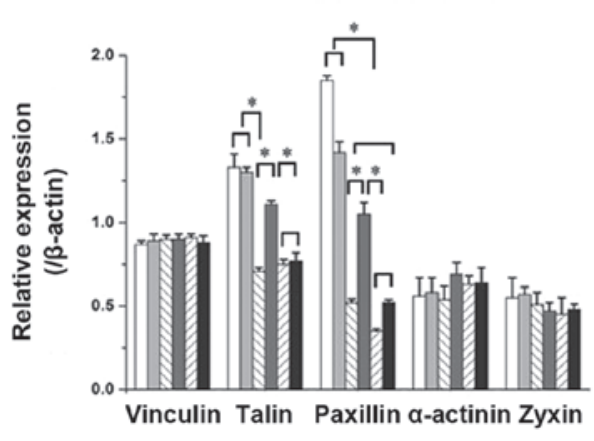

B HepG2

$\begin{array}{llllll}0 & 5 & 10 & 30 & 60 & 120\end{array}(\mathrm{~min})$

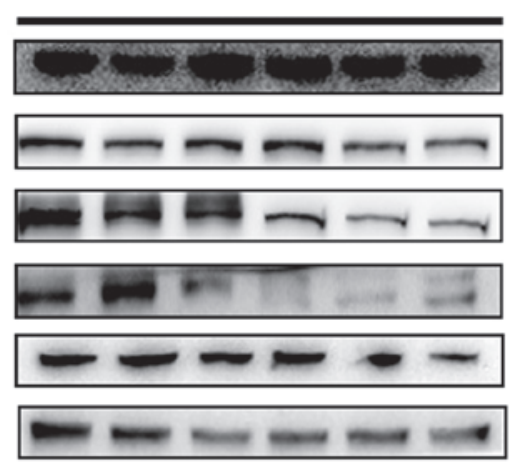

D $\square$ Control $\square 5 \mathrm{~min} \square 10 \mathrm{~min}$ $\square 30 \mathrm{~min} \square 60 \mathrm{~min}=120 \mathrm{~min}$

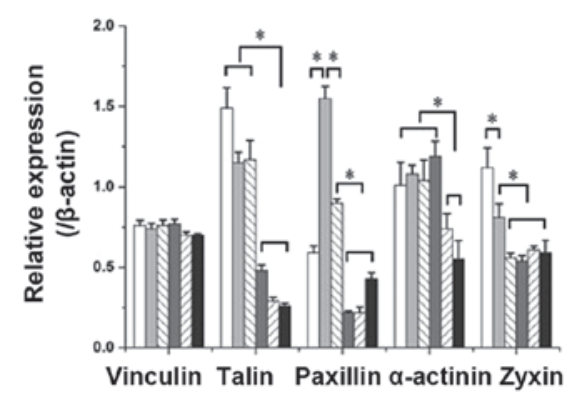

Figure 6. Effect of Y15 on the expression level of focal adhesion (FA) components in two cell lines within $2 \mathrm{~h}$. Expression level of vinculin, talin, paxillin, $\alpha$-actinin and zyxin within $2 \mathrm{~h}$ in (A) endothelial cells and (B) hepatoblastoma cells with inhibition of FAK. (C and D) Quantification of each protein expression level by image analysis of the western blot bands in (A and B). The expression level of $\beta$-actin in each group was used as an internal control, and the relative expression levels were calculated. Data are presented as means \pm standard error of the mean from three independent experiments. "P<0.05 denotes statistically significant differences.

exhibited a slight decrease, while that of $\alpha$-actinin exhibited a slight increase at 10-30 min, but there were no significant differences among groups (Fig. 6A).

Similar to ECs, increased duration of $50 \mu \mathrm{M}$ Y15 treatment did not affect the vinculin level in HepG2 cells (Fig. 6B). The expression of talin and paxillin in HepG2 cells exhibited a similar tendency, remaining at a lower level after $30 \mathrm{~min}$. There was no significant change in talin expression within $10 \mathrm{~min}$, but the level of paxillin initially increased at 5 min compared with the control $(\mathrm{P}<0.05$; Fig. 6B). Another difference between the two cell types is that inhibition of FAK significantly affected zyxin and $\alpha$-actinin expression in HepG 2 cells, with a significant decrease in zyxin expression at $10 \mathrm{~min}$ and the $\alpha$-actinin level at $60 \mathrm{~min}$ (Fig. 6B). These results demonstrated that partial FA complexes disassembled with inhibition of FAK, resulting in cell detachment and inhibition of cell adhesion. Furthermore, inhibition of FAK exerted different time-dependent effects on FA components in the two cell lines.

Expression and distribution of PI3K/AKT signaling with FAK inhibition. The autophosphorylation of FAK at Y397 is a binding site for Src and PI3K and, as downstream molecules of FAK, activated PI3K/AKT signaling events are crucial in regulating cell viability and migration. The $\mathrm{SH} 2$ domain phosphorylation of the p85 subunit of PI3K binding to FAK at Y397 may activate the p110 catalytic subunit of the PI3K/AKT signaling pathway. Therefore, PI3K/AKT signaling was investigated to determine whether inhibition of FAK induces changes in the PI3K/AKT pathway in the two cell lines. The PI3K/AKT expression levels with inhibition of FAK are shown in Fig. 7. Of note, the results demonstrated that the PI3K expression in response to FAK inhibitor treatment was opposite in the two cell lines (Fig. 7A and B). In endothelial EA.hy926 cells, blocking FAK increased the PI3K level during the initial $5 \mathrm{~min}$, which then gradually decreased to a relatively lower level. However, weaker expression of PI3K was found during the first 5-10 min in HepG2 cells when FAK was inhibited, subsequently increasing at $30 \mathrm{~min}$ and reaching a maximum level at $1 \mathrm{~h}$. The result was opposite in terms of PI3K expression in the two cell lines, but it was consistent with the expression of tFAK (Fig. 4A and B).

AKT1 may be activated and phosphorylated at Thr308 and Ser473 in a PI3K-dependent as well as -independent manner (22). Therefore, tAKT1 and pAKT1 were examined, and the relative ratio (pAKT/tAKT) was calculated in the two cell lines according to the results of western blot analyses. The results revealed a statistically significant difference of pAKT/tAKT in EA.hy926 cells during the initial $30 \mathrm{~min}$ 

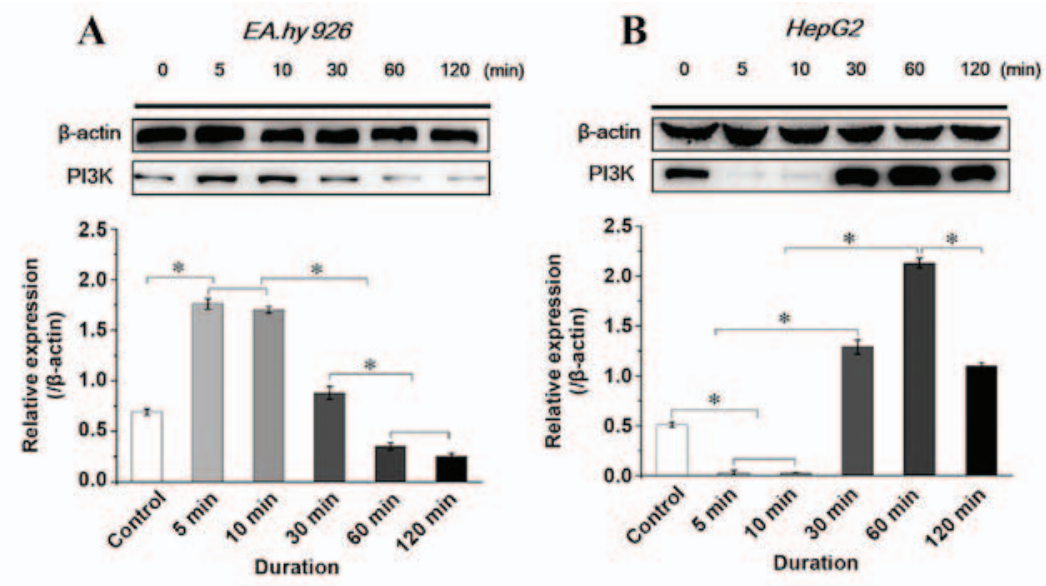

C

D
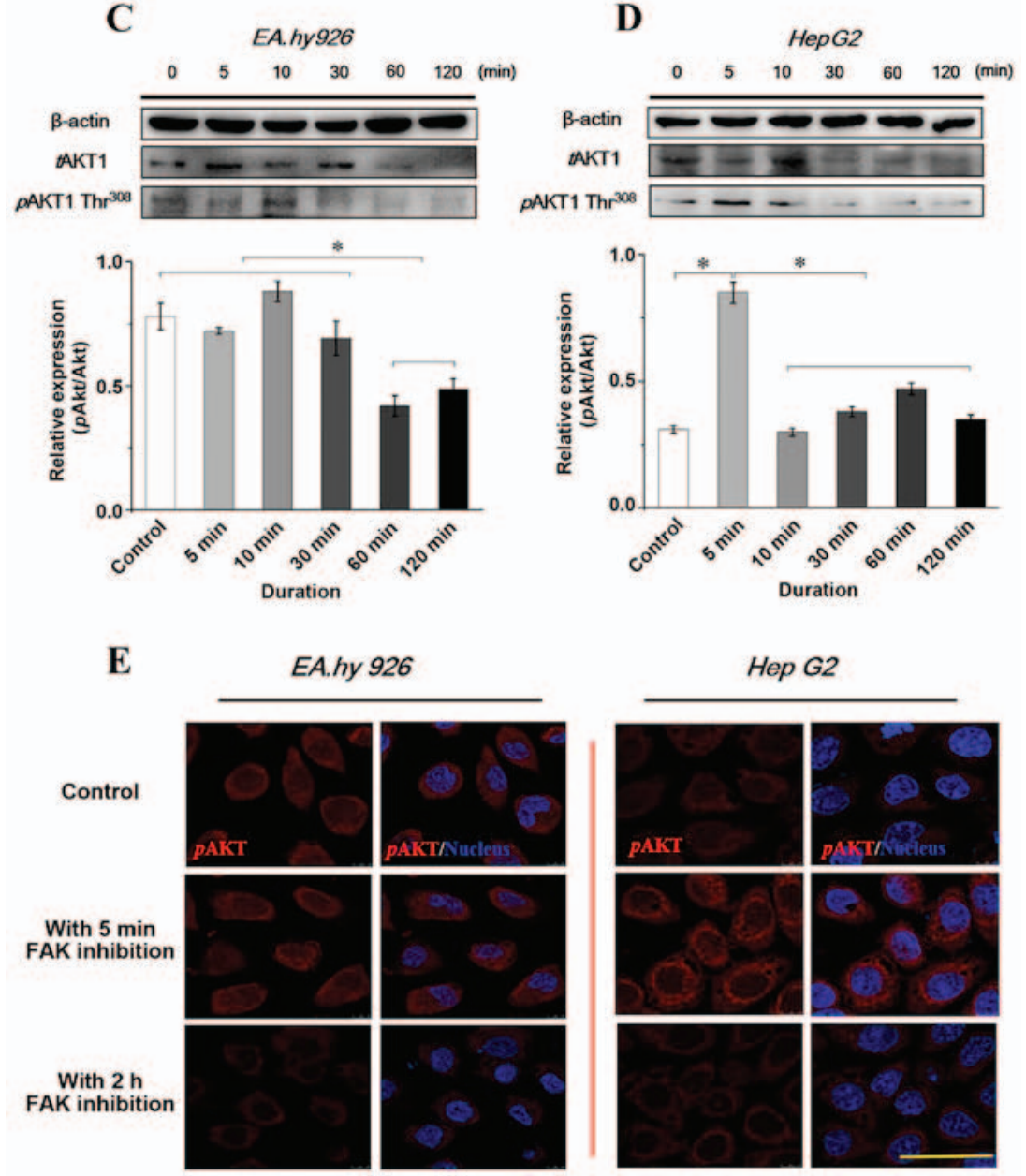

Figure 7. Inhibition of focal adhesion kinase (FAK) induced phosphatidylinositol 3-kinase (PI3K), AKT and phosphorylated AKT (pAKT at Thr308) in the two cell lines within $2 \mathrm{~h}$. Expression level of PI3K by western blot assays and quantification of PI3K expression level by image analysis of the western blot bands within $2 \mathrm{~h}$ in (A) endothelial cells and (B) hepatoblastoma cells, respectively, with inhibition of FAK. The expression level of $\beta$-actin in each group was used as an internal control, and relative expression level were calculated. Expression level of pAkt by western blot assays and quantification of pAKT in total AKT (tAKT) expression by image analysis of the western blot bands in (C) endothelial cells and (D) hepatoblastoma cells. "P<0.05 denotes a statistically significant difference. (E) Immunofluorescence analysis of the effects of the distribution and expression of pAKT (red) proteins with inhibition of FAK at 5 min and $2 \mathrm{~h}$ (blue, DAPI-stained nuclei); scale bar, $20 \mu \mathrm{m}$. DAPI, 4',6-diamidino-2-phenylindole.

compared with that after $30 \mathrm{~min}$, while the pAKT/tAKT ratio at 5 min in HepG2 cells exhibited a significant difference compared with other groups $(\mathrm{P}<0.05$; Fig. $7 \mathrm{C}$ and D). Furthermore, the distribution of pAKT was examined by immunofluorescence staining (Fig. 7E). With the 2-h inhibition of FAK, the expression levels of pAKT decreased in both endothelial and hepatoblastoma cells, consistently with the western blot results.
Time-dependent expression and distribution of Rho GTPases with addition of Y15. Rho family GTPases (RhoA, Rac1 and $\mathrm{Cdc42}$ ) result in direct local actin assembly to form stress fibres, lamellipodia or filopodia, respectively, and regulate cell polarity and motility through their effects on the cytoskeleton, membrane trafficking and cell adhesion (23). The Rho family small GTPases are important regulators of actin dynamics that 
A

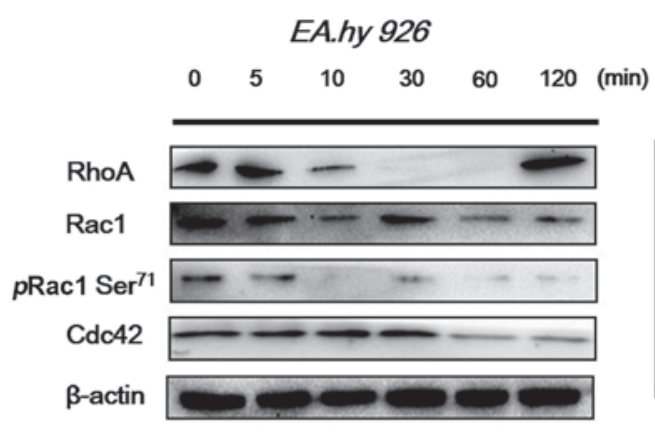

B

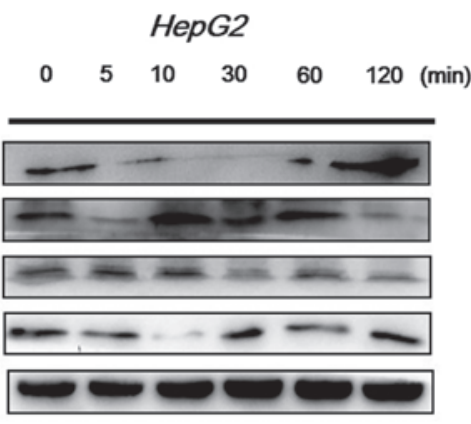

C

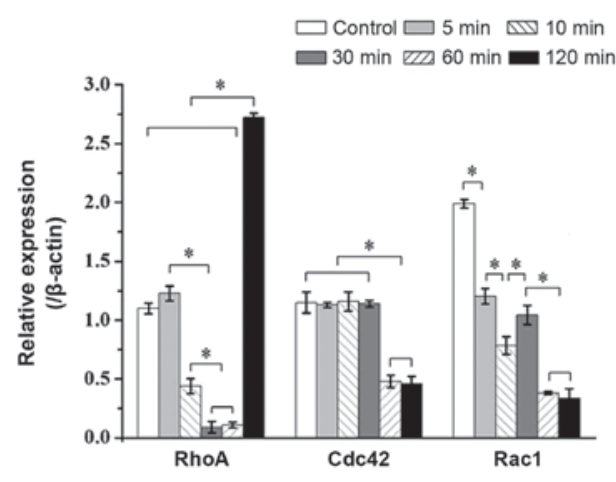

E

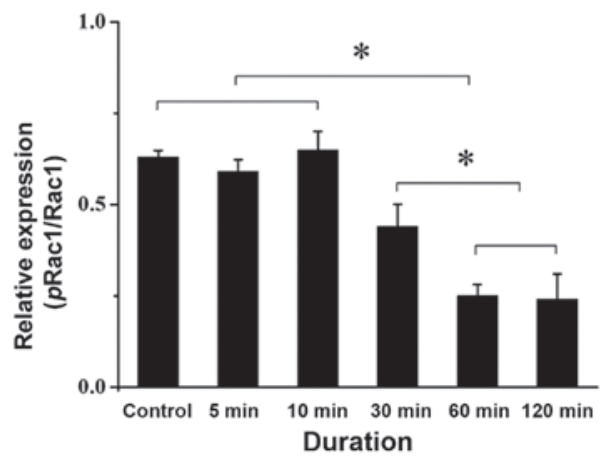

D

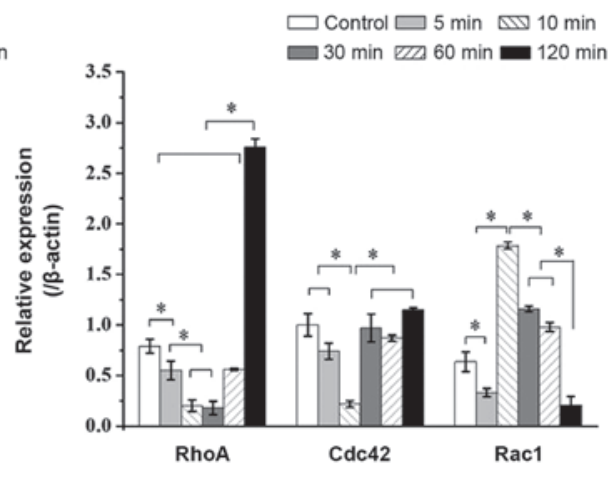

F

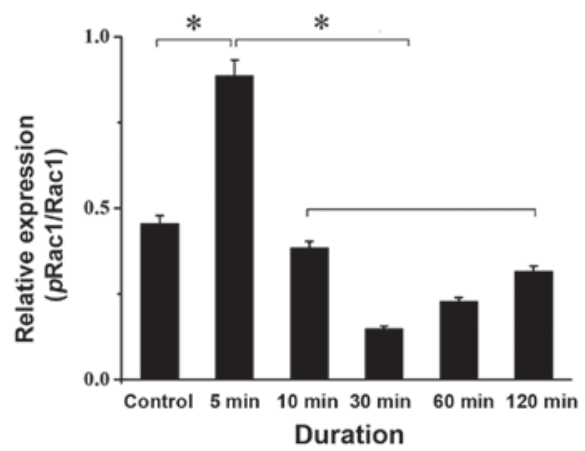

Figure 8. Effect of focal adhesion kinase (FAK) inhibitor on the expression level of small G-proteins-RhoA, pRac1 and Cdc42 in the two cell lines within $2 \mathrm{~h}$. Expression level of RhoA, phosphorylated Rac1 (pRac1) and Cdc42 proteins with inhibition of FAK within $2 \mathrm{~h}$ in (A) endothelial cells and (B) hepatoblastoma cells. (C and D) Quantification of each protein expression level by image analysis of the western blot bands in (A and B). The expression level of $\beta$-actin in each group was used as an internal control, and the relative expression levels were calculated. Quantification of pRac1 in total Rac1 expression by image analysis of the western blot bands in $(\mathrm{E})$ endothelial cells and $(\mathrm{F})$ hepatoblastoma cells. Values are presented as the mean \pm standard deviation, $\mathrm{n}=3$. ${ }^{*} \mathrm{P}<0.05$ denotes statistically significant differences compared with other groups.

potentiate cell migration. Cdc42 and Racl act at the leading edge of the cell to induce cell polarization and lamellipodia formation, respectively, whereas RhoA acts in the cell body to facilitate contraction (10). The phosphorylation of Racl at Ser71 (pRac1) predominantly modulates affinity to guanine nucleotide dissociation inhibitor and subcellular localization of GTPases, negatively regulating activation (24). As the downstream molecules of the integrin-FAK signaling pathway associated with cell adhesion and migration, the expression of RhoA, pRac1 and Cdc42 was examined following inhibition of FAK. With FAK inhibition for $2 \mathrm{~h}$, the expression level of
RhoA decreased in both endothelial and hepatoblastoma cells at 5-10 min, but had increased at $2 \mathrm{~h}$ (Fig. 8A and B), which is consistent with previous results, indicating that inhibition of FAK induced the retraction of lamellipodia at the cell protrusions and the formation of filamentous stress fibers in the cell body (Fig. 3). The total expression and phosphorylation levels at Ser71 of Rac1 were different between the two cell types; the expression of Rac1 in EA.hy926 cells decreased during the initial $5 \mathrm{~min}$, and pRacl was also lower after $5 \mathrm{~min}$ (Fig. 8A). While the expression of Racl in HepG2 cells decreased with FAK inhibition during the initial $5 \mathrm{~min}$, and immediately 


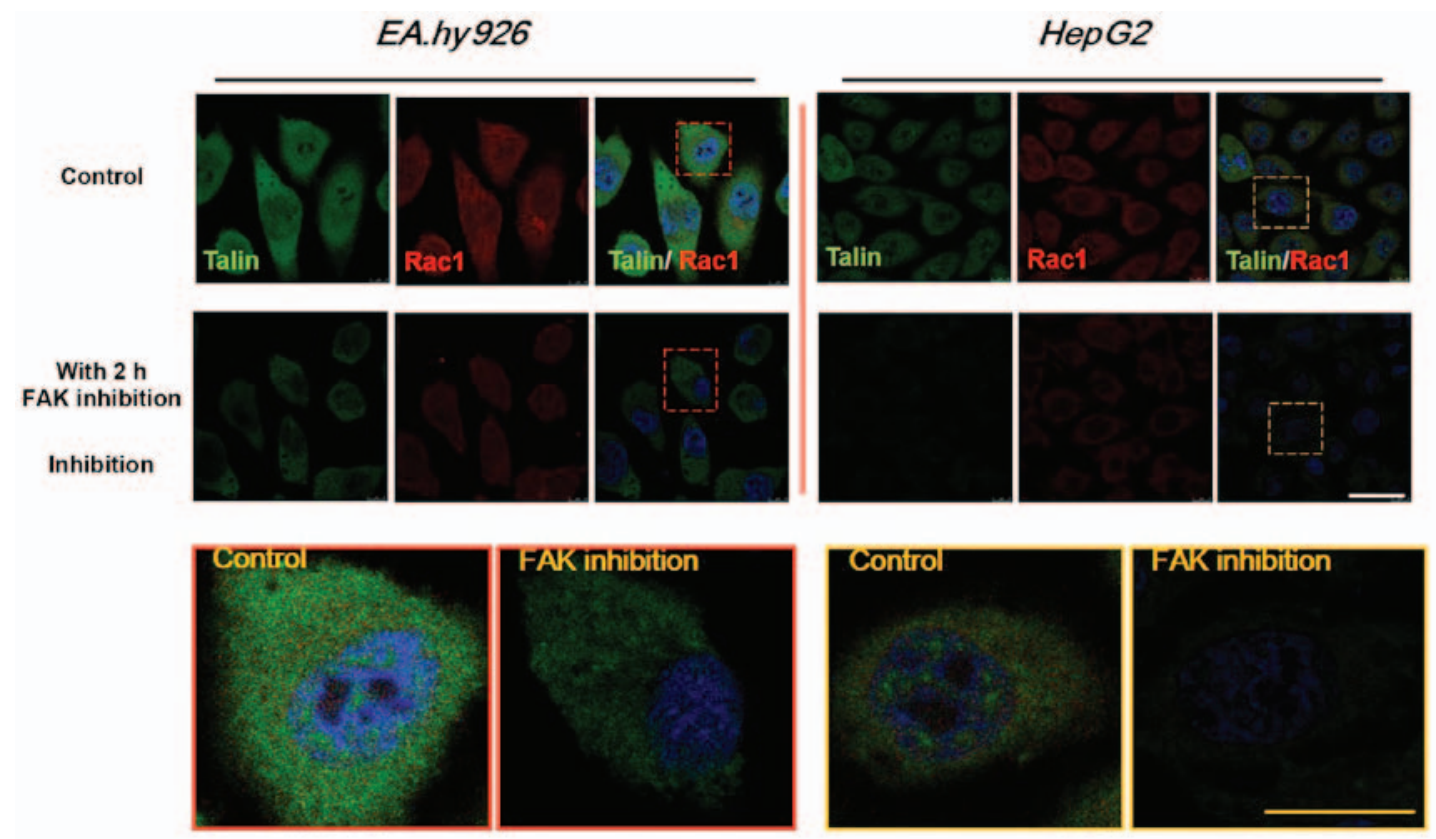

Figure 9. Effects of the distribution and expression of Rac1 (red) and talin (green) proteins with inhibition of focal adhesion kinase (FAK) after $2 \mathrm{~h}$ by double-labeled immunofluorescence staining (blue, DAPI-stained nuclei); white scale bar, $20 \mu \mathrm{m}$. Enlarged images of the designated regions, labeled by red (EA.hy926) and yellow square (HepG2) frames to show the detailed distribution in single cells; yellow scale bar, $10 \mu \mathrm{m}$. DAPI, 4',6-diamidino-2-phenylindole.

increased and remained at a higher level thereafter, pRac1 exhibited a lower level at 10 min (Fig. 8B). The results revealed a statistically significant difference of $\mathrm{pRac1} / \mathrm{Rac} 1$ in EA.hy926 cells during the initial 10 min compared with that thereafter, while the pRac1/Rac1 ratio at 5 min in HepG2 cells exhibited significant differences compared with other groups $(\mathrm{P}<0.05$; Fig. $8 \mathrm{C}$ and $\mathrm{D})$. As regards the $\mathrm{Cdc} 42$ level in ECs with inhibition of FAK, it was similar compared with that in the control group from the initial $5 \mathrm{~min}$ up to $30 \mathrm{~min}$, but decreased from $30 \mathrm{~min}$ to $1 \mathrm{~h}$ (Fig. 8A). In HepG2 cells, the expression of $\mathrm{Cdc} 42$ fluctuated, exhibiting a relative lower level at $10 \mathrm{~min}$, which recovered thereafter and was maintained at a higher level after $30 \mathrm{~min}$ (Fig. 8B). The time-dependent difference in Rho GTPase expression indicates different mechanisms of FAK-mediated migration behavior in various types of cells.

Distribution of FA proteins (talin) and Rho GTPases (Racl) with FAK inhibition. To further investigate the distribution of FA complexes and Rho GTPases, the cytoskeletal protein talin, which binds to integrin $\beta$ tails to form intercellular FA plaques associated with cell adhesion, and the Rho family GTPase Racl, which mediates lamellipodia formation and regulates cell migration behavior, were selected to study their respective distribution by double-labeled immunofluorescence analysis. As shown in Fig. 9, talin (green) and Rac1 (red) were mainly distributed in the entire cytoplasm. The expression levels of talin and Racl were downregulated with FAK inhibition for $2 \mathrm{~h}$, consistently with the western blot results for talin (Fig. 6) and Rac1 (Fig. 8). However, the expression of talin exhibited a more prominent decrease, with weakness of fluorescence intensity in HepG2 cells after $2 \mathrm{~h}$ of Y15 treatment, while the expression of talin in EA.hy926 cells exhibited a relatively mild downregulation. It was suggested that inhibition of total and phosphorylated FAK provided feedback signals to FA components, which may result in cell detachment, and also exert stronger effects on downstream Rho GTPases, which may weaken cell motility.

\section{Discussion}

Tumor-induced angiogenesis results from neovascularization of migrated ECs in solid tumors. Once adequate vasculature has been developed and established, the tumor invades the vessel wall and spreads to distant organs to form dormant micrometastases (25). Therefore, controlling tumor-associated angiogenesis is a promising strategy in limiting cancer progression.

The migration of endothelial and cancer cells plays a key role in the process of tumor-induced angiogenesis. Cell migration is an integrated process requiring continuous, coordinated assembly and disassembly of adhesion structures. To investigate the time-dependent differences in FAK-dependent signals in various cell lines, VECs and hepatoblatoma cells were selected for the experiments. In the present study, EA.hy926 cells were used rather than original VECs, as they exhibit a higher affinity to substrate, they express EC markers to the same extent as HUVECs, particularly vWF, PECAM-1, ICAM-1, E-selectin, and uptake of DiI-Ac-LDL, and have no tumorigenic potential, whereas they have been widely used to investigate different aspects of EC biology. By using the EA.hy926 cells as a model cell line, the expression level of integrins could be accurately studied, and it may help to better describe the direct effect of FAK inhibition on integrin signals (primary ECs, such as HUVECs, exhibit low affinity to tissue culture polystyrene without fibronectin or collagen pre-coating). However, the marked phenotype differences between EA.hy926 cells and primary VECs should be noted (26). The human hepatoblastoma cell line, HepG2, was selected as an in vitro model system for the study of adhesion and migration of tumor cells. Integrin- and 
growth factor-stimulated migratory cues were considered as significant events for activating FAK (27).

It has been proved that endothelial FAK is crucial for vascular network stability, cell survival and lamellipodia formation (28). Increased level of FAK was found in a variety of human tumors, and inhibition of FAK reduced tumor formation in the early stages (29), suggesting that FAK may be a new therapeutic target in cancer (30). The FAK inhibitor used in the present study was selected by Golubovskava et al (19), who reported that treatment with Y15 effectively decreased Y397 phosphorylation in BT474 breast carcinoma cells at $8 \mathrm{~h}$. Their studies also reported that this small-molecule FAK inhibitor increased cancer cell apoptosis and decreased tumor growth $(31,32)$. Thus, targeting the Y397 site may be an effective therapeutic approach to developing novel FAK inhibitors (33-36).

However, the role of FAK in cell migration and metastasis remains controversial in various cell types (37). It has been demonstrated that the overexpression of wild-type FAK in various different cell types may enhance cell migration (17). In HeLa cells, reduced expression level of FAK by siRNA and FAK-null were associated with increased cell motility, while FAK-null fibroblasts derived from $\mathrm{FAK}^{-/}$embryos exhibited reduced cell motility. FAK-deficient ECs exhibit defective but not reduced motility (38). Although in different cancer cell types, a substantial body of evidence demonstrated the contradictory roles of FAK as a positive or negative regulator of tumor cell migration and metastasis (37). In addition, elevated expression of FAK in cancer cells had been correlated with increased migration and invasiveness. Hauck et al (39) found that inhibition of FAK expression reduced the migration and invasion of EGF-stimulated human carcinoma cells (A549). Our results also supported the conclusion that inhibition of FAK was able to decrease the migration behavior of both ECs and hepatoblastoma cells. Additionally, inhibition of FAK exerted different time-dependent effects on tFAK and pFAK expression in ECs and hepatoblastoma cells. The tFAK level in ECs gradually decreased with increased duration of Y15 treatment. Of note, the tFAK level rapidly declined in HepG2 cells, suggesting that these cells are sensitive to this type of small-molecule compound FAK inhibitor, and FAK signaling is possibly the most dominant pathway in regulating HepG2 cell functions. However, other evidence supported that dephosphorylation of FAK increased tumor cell motility, invasion and metastasis in various human carcinoma cells (40). Furthermore, FAK signaling has been shown to participate in the process of transforming growth factor- $\beta$-induced epithelial-to-mesenchymal transition in hepatocytes (41). Kallergi et al (42) demonstrated that activation of FAK/PI3K/Rac1 signaling regulated actin reorganization and inhibited cell motility in A375 melanoma cells. In the present study, a simple inhibitor technique and scratch wound assays were used for cell migration analysis, and some crucial proteins in integrin-induced signaling pathways were extensively investigated to reveal possible alterations in the mechanisms of cell adhesion and migration under FAK inhibition.

The effect of integrins on the phosphorylation of FAK and the downstream signaling events associated with cell adhesion and migration in various cells has been widely investigated. Vinculin and the actin-binding protein talin, as the ligands of $\beta$ integrin cytoplasmictails, assemble aroundenriched integrins at cell adhesion sites to form nascent FA plaques (43). The maturation of intracellular nascent FAs involves a sequential cascade of compositional changes. At the early phase of integrin activation, the adapter protein paxillin is recruited and integrins are clustered into FAs. The detailed sequence of events leading to the assembly of adhesion complexes remains unclear (44). The cluster of FA complex recruits and binds FAK via the C-terminal FA targeting (FAT) domain. The initial tyrosine phosphorylation at the Y397 site of FAK may subsequently result in phosphorylation of additional multiple tyrosine sites (Y-576, -577 and -925). FAK preferentially interacts with the tyrosine phosphorylated paxillin (p-pax), and its recruitment is implicated in the high turnover of focal complexes and FA translocation. The p-pax is present in focal complexes, but not in fibrillar adhesions (45). Recently, Lawson et al (46) demonstrated that FAK promotes talin recruitment to nascent adhesions occurring independently from talin binding to $\beta 1$ integrins. In the present study, we observed that gradually decreasing FAK in ECs by an inhibitor significantly downregulated the expression levels of integrin $\alpha 2, \alpha 5$ and $\beta 3$ at 5-10 $\mathrm{min} ; \alpha 2$ and $\beta 3$ returned to higher levels with longer duration of treatment, but the $\alpha 5$ subunit continued to decrease with increasing treatment duration. The inhibition of FAK in HepG2 cells has different inhibition level in different treatment durations, and resulted in relatively lower levels of $\alpha 2$ and $\alpha 5$, but a higher level of $\beta 1$ over 30-60 min (Fig. 5). These results demonstrated that inhibition of FAK transmitted feedback signals to upstream integrins in both types of cells. The difference in tFAK and pFAK expression suggested the presence of diverse mechanisms in the two cell lines. Some evidence indicated that lack of FAK (by knockout, FAK siRNA or inhibition) in cells may activate compensatory effects by other signaling molecules. The compensatory switch from FAK to Pyk2 (FAK-related proline-rich tyrosine kinase 2) was reported in angiogenesis in adult mice lacking endothelial FAK, suggesting the adaptive capacity of cells to switch to Pyk2-dependent signaling following deletion or inhibition of FAK $(47,48)$. Therefore, some potential signals possibly compensate for the loss of FAK, and induce transient upregulation of pFAK in ECs. In HepG2 cells, the Y15 inhibitor sharply decreased total FAK and $\beta 1$ expression during the initial $5 \mathrm{~min}$, indicating rapid degradation of FAK, as it directly binds to the $\beta 1$ cytoplasmic domain. We hypothesized that HepG2 cells were sensitive to this type of small-molecule FAK inhibitor, and FAK signaling was possibly the most dominant pathway in regulating HepG2 cell functions. Furthermore, similar changes in the $\alpha 5$ and $\beta 3$ subunits were found in the two different cell types. Integrin $\alpha 5$ is primarily regarded as the fibronectin receptor, while $\beta 3$ non-covalently connecting to the $\alpha \mathrm{V}$ subunit regulates cell migration speed. The different expression levels of the $\alpha 2$ and $\beta 1$ subunits in the two cell types suggested changes in different ECM proteins with FAK inhibition, which may control cell adhesion, spreading, migration and detachment with specified treatment durations.

As mentioned above, the FA components recruit actin filaments to the cytoplasmic domain of integrins, and contribute to stabilization of cell adhesion. As is known, the recruitment of paxillin, which contains binding sites at its LIM domains that directly bind to the FAT domain of FAK (49), and talin, 
plays a central role in the first step of focal complex formation following initial integrin engagement, while vinculin acts in linking the actin cytoskeleton to FAs as a paxillin-binding partner. Our results demonstrated that both talin and paxillin in the two cell lines exhibited a gradually downregulated tendency, while vinculin maintained a stable expression level over the duration of FAK inhibition (Fig. 6). Long-lasting inhibition of FAK possibly resulted in the degradation of paxillin and talin, and turnover of FA, which regulate morphological changes and detachment in various cells (Fig. 3). However, the decrease in FAK expression with inhibition did not significantly affect vinculin, in part because it indirectly binds to FA as a paxillin-binding partner, participating in the formation of FAs.

FAK is considered to be upstream of PI3K regulating cell apoptosis and other functions (50). Activated FAK, serving as a scaffold or adaptor, provides a binding site and recruits a number of signaling molecules for Src family kinases and PI3K at SH2 domains, activating a cascade of downstream signaling pathways. The phosphorylation of FAK at the Y397 site is known to serve as a binding site for the $\mathrm{p} 85$ subunit of PI3K, and activated PI3K can stimulate several intermediates, including AKT, which is required for FAK to promote cell migration (51). Inhibition of FAK pharmacologically or by dominant-negative FAK, attenuated the phosphorylation of p85 subunit of PI3K and AKT (50), and it is consistent with our results from EA.hy926 cells (Figs. 4 and 7A and C). However, the expression of AKT1 was downregulated in HepG2 cells, which was in contrast to PI3K (Fig. 7B and D), indicating that AKT was likely activated independently of PI3K. Thamilselvan et al (7) reported that FAK siRNA did not affect the activation of PI3K induced by pressure, but blocked AKT phosphorylation. The difference between EA.hy926 and HepG2 cells in response to the same stimuli, suggested the diverse functional role of FAK/PI3K/pAKT1 signaling in controlling the motility of various types of cells.

Rho family GTPases, including RhoA, Rac1 and Cdc42, are key regulators of actin dynamics and cell adhesion/migration in a variety of cellular processes. The contribution of FAK to actin remodeling, which is required for cell migration, is mediated through binding to Rho protein effectors and subsequent effects on Rho GTPases. FAK may up- and downregulate the Rho GTPases by modulating various upstream regulators (52). Ren et al (53) indicated that FAK is required for Rho inhibition to promote FA turnover and cell migration. In the present study, the expressions of RhoA, Rac1 and Cdc42 under FAK inhibition were generally downregulated, but reactivated in different treatment durations. RhoA was reactivated and exhibited a higher level at $2 \mathrm{~h}$ in both endothelial and hepatoblastoma cells, while Rac1 and Cdc42 in hepatoblastoma cells exhibited high levels after 10 and 30 min of FAK inhibition (Fig. 8A and B). Combined with previous cell migration analysis findings, cell motility was significantly inhibited by long-lasting FAK inhibition ( $24 \mathrm{~h}$ ) compared with control cells (Fig. 1). This time-dependent effects of Rho GTPases in response to FAK inhibition prompted us to investigate the mechanisms of blocking cell migration in our future study. However, it should be noted that only total expression and phosphorylated levels of Rac and Rho were examined in the present study, while the activation of Rho GTPases should also be addressed.

In the present study, the time-dependent effects of FAK inhibition on integrin-induced signaling pathways associated with endothelial and hepatoblastoma cell migration in tumor angiogenesis were investigated. Our results demonstrated that the inhibition of FAK promoted cell detachment by decreasing the expression of FA components (talin and paxillin), and inhibiting cell motility by reducing the levels of Rho GTPases (Rac1, Cdc42 and RhoA). Most signaling proteins in the two cell lines exhibited a different time-dependent expression within $2 \mathrm{~h}$ of FAK inhibitor treatment, suggesting that the mechanisms underlying FAK-mediated migration behaviors differ between various types of cells. Elucidating the potential mechanism may help design novel drugs targeting FAK to inhibit endothelial and cancer cell migration in tumor angiogenesis.

\section{Acknowledgements}

Not applicable.

\section{Funding}

This study was supported in part by grants from the National Natural Science Foundation of China (nos. 11372203, 11172189 and 31300775), the program for New Century Excellent Talents in the University of China (no. NCET-060791), the Visiting Scholar Foundation of Key Laboratory of Biorheological Science and Technology (Chongqing University), the Specialized Research Fund for the Doctoral Program of Higher Education (no. 20120181120058) and the National Science Foundation for Fostering Talents in Basic Research of the National Natural Science Foundation of China (no. J1103604).

\section{Availability of data and materials}

The analyzed data sets generated during the study are available from the corresponding author on reasonable request.

\section{Authors' contributions}

YS and XL conceived and designed this project, and provided financial support. HY and MG performed the experiments. YM and LW contributed to the materials/analysis tools and analyzed the data. HY drafted the manuscript. All authors read and approved the final manuscript.

\section{Ethics approval and consent to participate}

Not applicable.

\section{Consent for publication}

Not applicable.

\section{Competing interests}

The authors declare that they have no competing interests. 


\section{References}

1. Weis SM and Cheresh DA: Tumor angiogenesis: molecular pathways and therapeutic targets. Nat Med 17: 1359-1370, 2011.

2. Lamalice L, Le Boeuf F and Huot J: Endothelial cell migration during angiogenesis. Circ Res 100: 782-794, 2007.

3. Friedl P and Wolf K: Tumour-cell invasion and migration: diversity and escape mechanisms. Nat Rev Cancer 3: 362-374, 2003.

4. Baker EL and Zaman MH: The biomechanical integrin. J Biomech 43: 38-44, 2010.

5. Pasapera AM, Schneider IC, Rericha E, Schlaepfer DD and Waterman CM: Myosin II activity regulates vinculin recruitment to focal adhesions through FAK-mediated paxillin phosphorylation. J Cell Biol 188: 877-890, 2010.

6. Hsia DA, Mitra SK, Hauck CR, Streblow DN, Nelson JA, Ilic D, Huang S, Li E, Nemerow GR, Leng J, et al: Differential regulation of cell motility and invasion by FAK. J Cell Biol 160: 753-767, 2003

7. Thamilselvan V, Craig DH and Basson MD: FAK association with multiple signal proteins mediates pressure-induced colon cancer cell adhesion via a Src-dependent PI3K/Akt pathway. FASEB J 21: 1730-1741, 2007.

8. Gurney SM, Forster P, Just U and Schwanbeck R: Suppression of the PI3K subunit $\mathrm{p} 85 \alpha$ delays embryoid body development and inhibits cell adhesion. J Cell Biochem 112: 3573-3581, 2011.

9. Clark EA, King WG, Brugge JS, Symons M and Hynes RO: Integrin-mediated signals regulated by members of the Rho family of GTPases. J Cell Biol 142: 573-586, 1998

10. Raftopoulou M and Hall A: Cell migration: Rho GTPases lead the way. Dev Biol 265: 23-32, 2004.

11. Tavora B, Batista S, Reynolds LE, Jadeja S, Robinson S, Kostourou V, Hart I, Fruttiger M, Parsons $M$ and Hodivala-Dilke KM: Endothelial FAK is required for tumour angiogenesis. EMBO Mol Med 2: 516-528, 2010.

12. Zhao X and Guan JL: Focal adhesion kinase and its signaling pathways in cell migration and angiogenesis. Adv Drug Deliv Rev 63: 610-615, 2011

13. Yom CK, Noh DY, Kim WH and Kim HS: Clinical significance of high focal adhesion kinase gene copy number and overexpression in invasive breast cancer. Breast Cancer Res Treat 128 647-655, 2011

14. Miyazaki T, Kato H, Nakajima M, Sohda M, Fukai Y, Masuda N, Manda R, Fukuchi M, Tsukada K and Kuwano H: FAK overexpression is correlated with tumour invasiveness and lymph node metastasis in oesophageal squamous cell carcinoma. Br J Cancer 89: 140-145, 2003.

15. Zhao J and Guan JL: Signal transduction by focal adhesion kinase in cancer. Cancer Metastasis Rev 28: 35-49, 2009.

16. Wozniak MA, Modzelewska K, Kwong L and Keely PJ: Focal adhesion regulation of cell behavior. Biochim Biophys Acta 1692 103-119, 2004.

17. Schlaepfer DD and Mitra SK: Multiple connections link FAK to cell motility and invasion. Curr Opin Genet Dev 14: 92-101, 2004

18. Lu ZJ, Ren YQ, Wang GP, Song Q, Li M, Jiang SS, Ning T, Guan YS, Yang JL and Luo F: Biological behaviors and proteomics analysis of hybrid cell line EAhy926 and its parent cell line A549. J Exp Clin Cancer Res 28: 16, 2009.

19. Golubovskaya VM, Nyberg C, Zheng M, Kweh F, Magis A, Ostrov D and Cance WG: A small molecule inhibitor, 1,2,4,5-benzenetetraamine tetrahydrochloride, targeting the y397 site of focal adhesion kinase decreases tumor growth. J Med Chem 51: 7405-7416, 2008.

20. Moissoglu K and Schwartz MA: Integrin signalling in directed cell migration. Biol Cell 98: 547-555, 2006.

21. Ezzell RM, Goldmann WH, Wang N, Parashurama N and Ingber DE: Vinculin promotes cell spreading by mechanically coupling integrins to the cytoskeleton. Exp Cell Res 231: 14-26, 1997.

22. Engelman JA: Targeting PI3K signalling in cancer: opportunities, challenges and limitations. Nat Rev Cancer 9: 550-562, 2009.

23. Ridley AJ: Rho GTPases and actin dynamics in membrane protrusions and vesicle trafficking. Trends Cell Biol 16: 522-529, 2006.

24. Schwarz J, Proff J, Hävemeier A, Ladwein M, Rottner K, Barlag B, Pich A, Tatge H, Just I and Gerhard R: Serine-71 phosphorylation of Racl modulates downstream signaling. PLoS One 7: e44358, 2012.

25. Hoeben A, Landuyt B, Highley MS, Wildiers H, Van Oosterom AT and De Bruijn EA: Vascular endothelial growth factor and angiogenesis. Pharmacol Rev 56: 549-580, 2004.
26. Unger RE, Krump-Konvalinkova V, Peters K and Kirkpatrick CJ: In vitro expression of the endothelial phenotype: comparative study of primary isolated cells and cell lines, including the novel cell line HPMEC-ST1.6R. Microvasc Res 64: 384-397, 2002

27. Sieg DJ, Hauck CR, Ilic D, Klingbeil CK, Schaefer E, Damsky CH and Schlaepfer DD: FAK integrates growth-factor and integrin signals to promote cell migration. Nat Cell Biol 2: 249-256, 2000

28. Braren R, Hu H, Kim YH, Beggs HE, Reichardt LF and Wang R: Endothelial FAK is essential for vascular network stability, cell survival, and lamellipodial formation. J Cell Biol 172: 151-162, 2006.

29. van Nimwegen MJ, Verkoeijen S, van Buren L, Burg D and van de Water B: Requirement for focal adhesion kinase in the early phase of mammary adenocarcinoma lung metastasis formation. Cancer Res 65: 4698-4706, 2005.

30. McLean GW, Carragher NO, Avizienyte E, Evans J, Brunton VG and Frame MC: The role of focal-adhesion kinase in cancer - a new therapeutic opportunity. Nat Rev Cancer 5: 505-515, 2005.

31. Beierle EA, Ma X, Stewart J, Nyberg C, Trujillo A, Cance WG and Golubovskaya VM: Inhibition of focal adhesion kinase decreases tumor growth in human neuroblastoma. Cell Cycle 9: 1005-1015, 2010

32. Hochwald SN, Nyberg C,Zheng M,Zheng D, Wood C, MassollNA, Magis A, Ostrov D, Cance WG and Golubovskaya VM: A novel small molecule inhibitor of FAK decreases growth of human pancreatic cancer. Cell Cycle 8: 2435-2443, 2009.

33. Infusino GA and Jacobson JR: Endothelial FAK as a therapeutic target in disease. Microvasc Res 83: 89-96, 2012.

34. Golubovskaya VM and Cance W: Focal adhesion kinase and p53 signal transduction pathways in cancer. Front Biosci (Landmark Ed) 15: 901-912, 2010.

35. Lim ST, Mikolon D, Stupack DG and Schlaepfer DD: FERM control of FAK function: implications for cancer therapy. Cell Cycle 7: 2306-2314, 2008

36. Eleniste PP and Bruzzaniti A: Focal adhesion kinases in adhesion structures and disease. J Signal Transduct 2012: 296450, 2012.

37. Zheng Y and Lu Z: Paradoxical roles of FAK in tumor cell migration and metastasis. Cell Cycle 8: 3474-3479, 2009.

38. Yano H, Mazaki Y, Kurokawa K, Hanks SK, Matsuda M and Sabe $\mathrm{H}$ : Roles played by a subset of integrin signaling molecules in cadherin-based cell-cell adhesion. J Cell Biol 166: 283-295, 2004

39. Hauck CR, Sieg DJ, Hsia DA, Loftus JC, Gaarde WA, Monia BP and Schlaepfer DD: Inhibition of focal adhesion kinase expression or activity disrupts epidermal growth factor-stimulated signaling promoting the migration of invasive human carcinoma cells. Cancer Res 61: 7079-7090, 2001.

40. Lu Z, Jiang G, Blume-Jensen P and Hunter T: Epidermal growth factor-induced tumor cell invasion and metastasis initiated by dephosphorylation and downregulation of focal adhesion kinase. Mol Cell Biol 21: 4016-4031, 2001.

41. Cicchini C, Laudadio I, Citarella F, Corazzari M, Steindler C, Conigliaro A, Fantoni A, Amicone L and Tripodi M: TGFbeta-induced EMT requires focal adhesion kinase (FAK) signaling. Exp Cell Res 314: 143-152, 2008.

42. Kallergi G, Agelaki S, Markomanolaki H, Georgoulias V and Stournaras C: Activation of FAK/PI3K/Racl signaling controls actin reorganization and inhibits cell motility in human cancer cells. Cell Physiol Biochem 20: 977-986, 2007.

43. Tadokoro S, Shattil SJ, Eto K, Tai V, Liddington RC, de Pereda JM, Ginsberg MH and Calderwood DA: Talin binding to integrin beta tails: a final common step in integrin activation. Science 302: 103-106, 2003.

44. Baumann K: Cell adhesion: FAK or talin: who goes first? Nat Rev Mol Cell Biol 13: 138-139, 2012

45. Zaidel-Bar R, Milo R, Kam Z and Geiger B: A paxillin tyrosine phosphorylation switch regulates the assembly and form of cell-matrix adhesions. J Cell Sci 120: 137-148, 2007.

46. Lawson C, Lim ST, Uryu S, Chen XL, Calderwood DA and Schlaepfer DD: FAK promotes recruitment of talin to nascent adhesions to control cell motility. J Cell Biol 196: 223-232, 2012.

47. Weis SM, Lim ST, Lutu-Fuga KM, Barnes LA, Chen XL, Göthert JR, Shen TL, Guan JL, Schlaepfer DD and Cheresh DA: Compensatory role for Pyk2 during angiogenesis in adult mice lacking endothelial cell FAK. J Cell Biol 181: 43-50, 2008.

48. Lim Y, Lim ST, Tomar A, Gardel M, Bernard-Trifilo JA, Chen XL, Uryu SA, Canete-Soler R, Zhai J, Lin H, et al: PyK2 and FAK connections to p190R ho guanine nucleotide exchange factor regulate RhoA activity, focal adhesion formation, and cell motility. J Cell Biol 180: 187-203, 2008 
49. Schaller MD: Paxillin: a focal adhesion-associated adaptor protein. Oncogene 20: 6459-6472, 2001.

50. Xia H, Nho RS, Kahm J, Kleidon J and Henke CA: Focal adhesion kinase is upstream of phosphatidylinositol 3-kinase/Akt in regulating fibroblast survival in response to contraction of type I collagen matrices via a beta 1 integrin viability signaling pathway. J Biol Chem 279: 33024-33034, 2004.

51. Reiske HR, Kao SC, Cary LA, Guan JL, Lai JF and Chen HC: Requirement of phosphatidylinositol 3-kinase in focal adhesion kinase-promoted cell migration. J Biol Chem 274: 12361-12366, 1999.

52. Myers JP, Robles E, Ducharme-Smith A and Gomez TM: Focal adhesion kinase modulates Cdc42 activity downstream of positive and negative axon guidance cues. J Cell Sci 125: 2918-2929, 2012.
53. Ren XD, Kiosses WB, Sieg DJ, Otey CA, Schlaepfer DD and Schwartz MA: Focal adhesion kinase suppresses Rho activity to promote focal adhesion turnover. J Cell Sci 113: 3673-3678, 2000.

(i) 9 This work is licensed under a Creative Commons Attribution-NonCommercial-NoDerivatives 4.0 International (CC BY-NC-ND 4.0) License. 